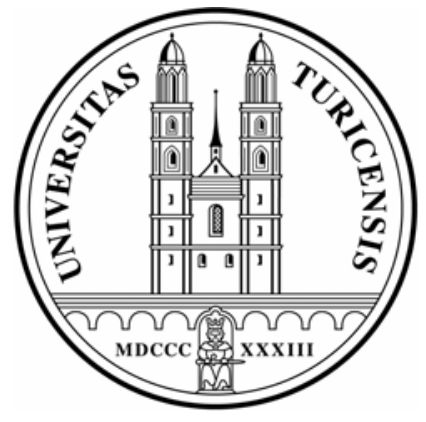

Institute for Empirical Research in Economics

University of Zurich

Working Paper Series

ISSN 1424-0459

Working Paper No. 319

\title{
Models of Stochastic Choice and Decision Theories: Why Both are Important for Analyzing Decisions
}

Pavlo Blavatskyy and Ganna Pogrebna

April 2007 


\title{
Models of Stochastic Choice and Decision Theories: Why Both are Important for Analyzing Decisions
}

\author{
Pavlo Blavatskyy ${ }^{\dagger}$ and Ganna Pogrebna
}

April 2007

\begin{abstract}
Economic research offers two traditional ways of analyzing decision making under risk. One option is to compare the goodness of fit of different decision theories using the same model of stochastic choice. An alternative way is to vary models of stochastic choice combining them with only one or two decision theories. This paper proposes to look at the bigger picture by comparing different combinations of decision theories and models of stochastic choice. We select a menu of seven popular decision theories and embed each theory in five models of stochastic choice including tremble, Fechner and random utility model. We find that the estimated parameters of decision theories differ significantly when theories are combined with different models. Depending on the selected model of stochastic choice we obtain different ranking of decision theories with regard to their goodness of fit to the data. The fit of all analyzed decision theories improves significantly when they are embedded in a Fechner model of heteroscedastic truncated errors (or random utility model in a dynamic decision problem).
\end{abstract}

Key words: Fechner model, random utility, tremble, expected utility theory, risk

JEL Classification codes: C93, D81

\footnotetext{
${ }^{*}$ We are grateful to Steffen Andersen, Christian Ewerhart, Glenn Harrison, Wolfgang Köhler, Morten Lau, Ulrich Schmidt, Francesco Trebbi, Peter Wakker, Nathaniel Wilcox and Fabrizio Zilibotti for their insightful comments. We also thank participants of research seminars at the University of Zurich (December 7, 2006), Max Planck Institute for Research on Collective Goods in Bonn (October 24, 2006), the University of Bonn (September 26, 2006), and the University of Innsbruck (May 4, 2006), the participants of the Economic Science Association European Meeting in Nottingham, United Kingdom (September 9, 2006) and the $12^{\text {th }}$ International Conference on The Foundation and Application of Utility, Risk and Decision Theory in Rome, Italy (June 24, 2006). Pavlo Blavatskyy acknowledges financial support from the Fund for Support of Academic Development at the University of Zurich. ${ }^{\dagger}$ Corresponding author, Institute for Empirical Research in Economics, University of Zurich, Winterthurerstrasse 30, CH-8006 Zurich, Switzerland, tel.: +41(0)446343586, fax: +41(0)446344978, e-mail: pavlo.blavatskyy@,iew.unizh.ch

University of Bonn, Department of Economics, BWL I, Adenauerallee 24-42, 53113 Bonn, tel.:+49(0)228736740, fax: +49(0)228735924, email: ganna.pogrebna@uni-bonn.de
} 


\section{Models of Stochastic Choice and Decision Theories: Why Both are Important for Analyzing Decisions}

Experimental studies on repeated decision making under risk find that individuals often do not choose the same alternative when they are faced with identical binary choice problem repeated within a short period of time. For instance, Camerer (1989) reports that $31.6 \%$ of subjects reverse their initial decision on the second repetition of a choice task. Starmer and Sugden (1989) observe a switching rate of 26.5\%. Hey and Orme (1994) find that $25 \%$ of repeated decisions are inconsistent, even when individuals are allowed to declare indifference. Ballinger and Wilcox (1997) report a median switching rate of $20.8 \%$.

An overwhelming majority of decision theories are deterministic i.e. they predict that an individual makes identical choices if a decision problem is repeated, unless she is exactly indifferent. Such a decision theory is typically embedded into a model of stochastic choice, when there is a need to relate a deterministic theory to stochastic data. Stochastic data can be either individual choice patterns from repeated decision making (e.g. Hey and Orme, 1994) or aggregate choice patterns from unrepeated decision making (e.g. Harless and Camerer, 1994). Thus, a model of stochastic choice serves as an intermediary, which translates a deterministic prediction of decision theories in a stochastic choice pattern that can be estimated by econometric methods on empirical data.

Much of empirical research on decision making under risk focuses on comparing numerous decision theories according to their goodness of fit to the behavioral patterns observed in the laboratory experiments. A researcher typically selects one model of stochastic choice and estimates several decision theories all embedded into this model. For example, Harless and Camerer (1994) estimate decision theories embedded in a tremble model and Hey and Orme (1994) estimate decision theories embedded in a 
Fechner model of homoscedastic random errors. A far less common procedure is to select one or two decision theories and to estimate them in conjunction with several models of stochastic choices (e.g. Carbone, 1997; Loomes et al., 2002). As Hey (2005) points out, the selection of a model of stochastic choice is generally considered to be of secondary importance with far more emphasis put on the selection of a decision theory. However, Buschena and Zilberman (2000) and Blavatskyy (2007) show that conclusions drawn from the estimation of decision theories embedded in one model of stochastic choice do not necessarily hold if theories are estimated with different models of stochastic choice.

In this paper we do not estimate several decision theories all embedded in one model of stochastic choice or just one decision theory embedded in several models of stochastic choice. To look at the big picture, we estimate seven popular decision theories each embedded in five models of stochastic choice that were proposed in the literature. In addition, we do not run a conventional laboratory experiment. Instead, we use data from a natural experiment, where representatives of a large fraction of the adult population choose between a risky lottery with large monetary stakes and an amount for certain.

Our main findings are as follows. Estimates of decision theories vary significantly when theories are embedded in different models of stochastic choice. In a static decision problem, the model that provides the best description of the data is a Fechner model of heteroscedastic truncated errors. In a dynamic decision problem, the performance of a Fechner model of heteroscedastic truncated errors is tied with a random utility model. The fit of a decision theory varies dependent on the model of stochastic choice. Across all models, the best explanation of the data is provided by either expected utility theory with expo-power utility function or rank-dependent expected utility theory. The theory with the 
worst fit (risk neutrality) combined with the best performing model of stochastic choice generally is at least as good as the best performing theory embedded in any other model.

The remainder of this paper is organized as follows. Models of stochastic choice are described in section 1 and decision theories are described in section 2. Section 3 presents the data from a natural experiment. Section 4 compares maximum likelihood estimates of each theory embedded in each model and their goodness of fit. Section 5 concludes.

\section{Models of Stochastic Choice}

\subsection{Tremble model}

Harless and Camerer (1994) argue that individuals generally choose among lotteries according to a deterministic decision theory, but there is a constant probability that this deterministic choice pattern reverses (as a result of pure tremble). Let $\boldsymbol{\theta}$ be a vector of parameters that characterize the parametric form of a decision theory and let $u(L, \boldsymbol{\theta})$ denote utility of a lottery $L$ according to this theory. In this paper we consider only binary choices between a risky lottery and a degenerate lottery that delivers one monetary outcome with probability one. According to Harless and Camerer (1994), the log-likelihood of observing $N$ decisions, when individuals choose a risky lottery $L_{i}$, $i \in\{1, \ldots, N\}$, over a monetary amount $O_{i}$ for certain, can be written as

$$
\begin{aligned}
L L_{R} & =\sum_{i=1}^{N} \log (1-p) \cdot I\left(u\left(L_{i}, \boldsymbol{\theta}\right)>u\left(O_{i}, \boldsymbol{\theta}\right)\right)+\sum_{i=1}^{N} \log (p) \cdot I\left(u\left(L_{i}, \boldsymbol{\theta}\right)<u\left(O_{i}, \boldsymbol{\theta}\right)\right)+ \\
& +\sum_{i=1}^{N} \log (1 / 2) \cdot I\left(u\left(L_{i}, \boldsymbol{\theta}\right)=u\left(O_{i}, \boldsymbol{\theta}\right)\right),
\end{aligned}
$$

and the log-likelihood of observing $M$ decisions, when individuals choose a monetary amount $O_{i}, i \in\{1, \ldots, M\}$, for certain over a risky lottery $L_{i}$, can be written as 


$$
\begin{aligned}
L L_{A} & =\sum_{i=1}^{M} \log (p) \cdot I\left(u\left(L_{i}, \boldsymbol{\theta}\right)>u\left(O_{i}, \boldsymbol{\theta}\right)\right)+\sum_{i=1}^{N} \log (1-p) \cdot I\left(u\left(L_{i}, \boldsymbol{\theta}\right)<u\left(O_{i}, \boldsymbol{\theta}\right)\right)+ \\
& +\sum_{i=1}^{N} \log (1 / 2) \cdot I\left(u\left(L_{i}, \boldsymbol{\theta}\right)=u\left(O_{i}, \boldsymbol{\theta}\right)\right)
\end{aligned}
$$

where $I(x)$ is an indicator function i.e. $I(x)=1$ if $x$ is true and $I(x)=0$ if $x$ is false, and $p \in(0,1)$ is probability of a tremble. Notice that a tremble occurs when the utility of a risky lottery is less than the utility of a sure amount but an individual chooses the risky lottery nonetheless; or when the risky lottery yields higher utility but an individual chooses the sure amount. Parameters $\boldsymbol{\theta}$ and $p$ are estimated to maximize log-likelihood $L L_{R}+L L_{A}$

\subsection{Fechner Model of Homoscedastic Random Errors}

Hey and Orme (1994) estimate a Fechner model of random errors, where a random error distorts the net advantage of one lottery over another (in terms of utility). Net advantage is calculated according to underlying deterministic decision theory. The error term is a normally distributed random variable with zero mean and constant standard deviation. According to Hey and Orme (1994), the log-likelihood of observing $N$ decisions, when individuals choose a risky lottery $L_{i}, i \in\{1, \ldots, N\}$, over a monetary amount $O_{i}$ for certain, can be written as

$$
L L_{R}=\sum_{i=1}^{N} \log \left(\Phi_{0, \sigma}\left[u\left(L_{i}, \boldsymbol{\theta}\right)-u\left(O_{i}, \boldsymbol{\theta}\right)\right]\right),
$$

and the log-likelihood of observing $M$ decisions, when individuals choose a monetary amount $O_{i}, i \in\{1, \ldots, M\}$, for certain over a risky lottery $L_{i}$, can be written as

$$
L L_{A}=\sum_{i=1}^{M} \log \left(1-\Phi_{0, \sigma}\left[u\left(L_{i}, \boldsymbol{\theta}\right)-u\left(O_{i}, \boldsymbol{\theta}\right)\right]\right)
$$


where $\Phi_{0, \sigma}[$.$] is the cumulative distribution function (cdf) of a normal distribution with$ zero mean and standard deviation $\sigma$. Parameters $\boldsymbol{\theta}$ and $\sigma$ are estimated to maximize combined log-likelihood $L L_{R}+L L_{A}$.

\subsection{Fechner Model of Heteroscedastic Random Errors}

Hey (1995) and Buschena and Zilberman (2000) extend a Fechner model of random errors by assuming that the error term is heteroscedastic, i.e. the standard deviation of errors is higher in certain decision problems, for example, when lotteries have many possible outcomes. Blavatskyy (2007) argues that individuals, who face risky lotteries with a smaller range of possible outcomes, have a lower volatility of random errors than individuals, who face risky lotteries with a wider range of possible outcomes. For example, an individual facing $50 \%-50 \%$ chance of $€ 1$ and $€ 5$ is likely to have a smaller variance of random errors than an individual facing 50\%-50\% chance of $€ 1$ and $€ 500$ 000. We will estimate a Fechner model of random errors when the standard deviation of random errors is proportionate to the difference between the utility of the highest outcome $\bar{x}$ and the utility of the lowest outcome $\underline{x}$ of a risky lottery $L$. Specifically, the log-likelihood of observing $N$ decisions, when individuals choose a risky lottery $L_{i}, i \in\{1, \ldots, N\}$, over a monetary amount $O_{i}$ for certain, can be written as

$$
L L_{R}=\sum_{i=1}^{N} \log \left(\Phi_{0, \sigma \cdot\left[u\left(\overline{\bar{x}}_{i}, \boldsymbol{\theta}\right)-u\left(\underline{x}_{i}, \boldsymbol{\theta}\right)\right]}\left[u\left(L_{i}, \boldsymbol{\theta}\right)-u\left(O_{i}, \boldsymbol{\theta}\right)\right]\right),
$$

and the log-likelihood of observing $M$ decisions, when individuals choose a monetary amount $O_{i}, i \in\{1, \ldots, M\}$, for certain over a risky lottery $L_{i}$, can be written as

$$
L L_{A}=\sum_{i=1}^{M} \log \left(1-\Phi_{0, \sigma \cdot\left[u\left(\bar{x}_{i}, \boldsymbol{\theta}\right)-u\left(\underline{x}_{i}, \boldsymbol{\theta}\right)\right]}\left[u\left(L_{i}, \boldsymbol{\theta}\right)-u\left(O_{i}, \boldsymbol{\theta}\right)\right]\right)
$$

As usual, parameters $\boldsymbol{\theta}$ and $\sigma$ are estimated to maximize total log-likelihood $L L_{R}+L L_{A}$. 


\subsection{Fechner Model of Heteroscedastic and Truncated Random Errors}

Blavatskyy (2007) extends a Fechner model of heteroscedastic errors by truncating the distribution of random errors so that an individual does not commit transparent errors. An example of such transparent error is the situation when an individual values a risky lottery more than its highest possible outcome for certain or when an individual values a risky lottery less than its lowest possible outcome for certain (known as a violation of the internality axiom).

In a binary choice between a risky lottery and a monetary amount for certain, a rational individual would always reject the amount, which is smaller than the lowest possible outcome of the risky lottery. Similarly, the individual would always accept an amount, which exceeds the highest possible outcomes of the risky lottery. However, according to a Fechner model presented in sections 1.2 and 1.3 there is a strictly positive probability that a decision maker commits such transparent error.

To disregard such transparent errors, the distribution of heteroscedastic Fechner errors is truncated from above and from below. Specifically, the log-likelihood of observing $N$ decisions, when individuals choose a risky lottery $L_{i}, i \in\{1, \ldots, N\}$, over a monetary amount $O_{i} \in\left[\underline{x}_{i}, \bar{X}_{i}\right]$ for certain, can be written as

$$
L L_{R}=\sum_{i=1}^{N} \log \left(\frac{\Phi_{0, \sigma \cdot\left[u\left(\bar{x}_{i}, \boldsymbol{\theta}\right)-u\left(\underline{x}_{i}, \boldsymbol{\theta}\right)\right]}\left[u\left(\bar{x}_{i}, \boldsymbol{\theta}\right)-u\left(L_{i}, \boldsymbol{\theta}\right)\right]-\Phi_{0, \sigma \cdot\left[u\left(\bar{x}_{i}, \boldsymbol{\theta}\right)-u\left(\underline{x}_{i}, \boldsymbol{\theta}\right)\right]}\left[u\left(O_{i}, \boldsymbol{\theta}\right)-u\left(L_{i}, \boldsymbol{\theta}\right)\right]}{\Phi_{0, \sigma \cdot\left[u\left(\bar{x}_{i}, \boldsymbol{\theta}\right)-u\left(\underline{x}_{i}, \boldsymbol{\theta}\right)\right]}\left[u\left(\bar{x}_{i}, \boldsymbol{\theta}\right)-u\left(L_{i}, \boldsymbol{\theta}\right)\right]-\Phi_{0, \sigma \cdot\left[u\left(\bar{x}_{i}, \boldsymbol{\theta}\right)-u\left(\underline{x}_{i}, \boldsymbol{\theta}\right)\right]}\left[u\left(\underline{x}_{i}, \boldsymbol{\theta}\right)-u\left(L_{i}, \boldsymbol{\theta}\right)\right]}\right),
$$

and the log-likelihood of observing $M$ decisions, when individuals choose a monetary amount $O_{i} \in\left[\underline{x}_{i}, \bar{x}_{i}\right], i \in\{1, \ldots, M\}$, for certain over a risky lottery $L_{i}$, can be written as

$$
L L_{A}=\sum_{i=1}^{M} \log \left(\frac{\Phi_{0, \sigma \cdot\left[u\left(\bar{x}_{i}, \boldsymbol{\theta}\right)-u\left(\underline{x}_{i}, \boldsymbol{\theta}\right)\right]}\left[u\left(O_{i}, \boldsymbol{\theta}\right)-u\left(L_{i}, \boldsymbol{\theta}\right)\right]-\Phi_{0, \sigma \cdot\left[u\left(\bar{x}_{i}, \boldsymbol{\theta}\right)-u\left(\underline{x}_{i}, \boldsymbol{\theta}\right)\right]}\left[u\left(\underline{x}_{i}, \boldsymbol{\theta}\right)-u\left(L_{i}, \boldsymbol{\theta}\right)\right]}{\Phi_{0, \sigma \cdot\left[u\left(\bar{x}_{i}, \boldsymbol{\theta}\right)-u\left(\underline{x}_{i}, \boldsymbol{\theta}\right)\right]}\left[u\left(\bar{x}_{i}, \boldsymbol{\theta}\right)-u\left(L_{i}, \boldsymbol{\theta}\right)\right]-\Phi_{0, \sigma \cdot\left[u\left(\bar{x}_{i}, \boldsymbol{\theta}\right)-u\left(\underline{x}_{i}, \boldsymbol{\theta}\right)\right]}\left[u\left(\underline{x}_{i}, \boldsymbol{\theta}\right)-u\left(L_{i}, \boldsymbol{\theta}\right)\right]}\right) .
$$


Notice that when a sure monetary amount is exactly equal to the lowest (highest) possible outcome of a risky lottery, an individual chooses the risky lottery with probability one (zero) and she chooses the sure amount with probability zero (one). As usual, parameters $\boldsymbol{\theta}$ and $\sigma$ are estimated to maximize combined log-likelihood $L L_{R}+L L_{A}$.

\subsection{Random Utility Model}

Loomes and Sugden (1995) argue that individual preferences over lotteries are stochastic and can be represented by a random utility model. Individual preferences over lotteries are captured by a decision theory with a parametric form that is characterized by a vector of parameters $\boldsymbol{\theta}$. We will assume that one of the parameters $\theta_{R} \in \boldsymbol{\theta}$ is normally distributed with mean $\mu$ and standard deviation $\sigma$ and the remaining parameters $\boldsymbol{\theta}_{-R}$ are non-stochastic. ${ }^{1}$ Let $\bar{\theta}_{R}\left(\boldsymbol{\theta}_{-R}\right)$ denote the value of parameter $\theta_{R}$ such that given other parameters $\boldsymbol{\theta}_{-R}$, an individual is exactly indifferent between a monetary amount $O$ for certain and a risky lottery $L$ i.e. $u\left(L,\left[\bar{\theta}_{R}\left(\boldsymbol{\theta}_{-R}\right), \boldsymbol{\theta}_{-R}\right]\right)=u\left(O,\left[\bar{\theta}_{R}\left(\boldsymbol{\theta}_{-R}\right), \boldsymbol{\theta}_{-R}\right]\right)$. Without a loss of generality, we can assume that for all parameter values above this threshold, i.e. $\theta_{R}>\bar{\theta}_{R}\left(\boldsymbol{\theta}_{-R}\right)$, an individual prefers the sure amount over the risky lottery (otherwise we can always define a new parameter $\theta_{R}^{*}=-\theta_{R}$ ).

The log-likelihood of observing $N$ decisions, when individuals choose a risky lottery $L_{i}, i \in\{1, \ldots, N\}$, over a monetary amount $O_{i}$ for certain, can be then written as

$$
L L_{R}=\sum_{i=1}^{N} \log \left(\Phi_{\mu, \sigma}\left[\bar{\theta}_{R}\left(\boldsymbol{\theta}_{-R}\right)\right]\right)
$$

\footnotetext{
${ }^{1}$ We do not assume that all parameters in vector $\boldsymbol{\theta}$ are jointly normally distributed because maximum likelihood estimation of such (non-linear) model requires numerical integration, which significant impacts the speed of computations. Even with only one stochastic parameter, the estimation of rank-dependent expected utility and disappointment aversion theory embedded into a random utility model took as long as two month on Pentium 4 3.0 GHz CPU.
} 
and the log-likelihood of observing $M$ decisions, when individuals choose a monetary amount $O_{i}, i \in\{1, \ldots, M\}$, for certain over a risky lottery $L_{i}$, can be written as

$$
L L_{A}=\sum_{i=1}^{M} \log \left(1-\Phi_{\mu, \sigma}\left[\bar{\theta}_{R}\left(\boldsymbol{\theta}_{-R}\right)\right]\right),
$$

Notice that the probability that an individual chooses a risky lottery over a monetary amount is simply the probability of observing preferences characterized by parameter $\theta_{R}<\bar{\theta}_{R}\left(\boldsymbol{\theta}_{-R}\right)$. Similarly, the likelihood that an individual chooses the sure amount is just the likelihood of observing parameter $\theta_{R}>\bar{\theta}_{R}\left(\boldsymbol{\theta}_{-R}\right)$. Parameters $\boldsymbol{\theta}_{-R}, \mu$ and $\sigma$ are estimated to maximize total log-likelihood $L L_{R}+L L_{A}$.

\subsection{Luce Choice Model (Strict Utility Model)}

Luce (1959) proposes a stochastic choice model (known as strict utility model) where the probability that a risky lottery $L$ is chosen over a monetary amount $O$ for certain can be written as $u(L, \boldsymbol{\theta})^{1 / \mu} /\left[u(L, \boldsymbol{\theta})^{1 / \mu}+u(O, \boldsymbol{\theta})^{1 / \mu}\right\rfloor$, where $\mu>0$ is a noise parameter. This model has been recently popularized by Holt and Laury (2002). It is well-known (e.g. Theorem 30 in Luce and Suppes, 1965) that Luce choice model can be rewritten as a Fechner model of homoscedastic random errors so that the probability that a risky lottery $L$ is chosen over amount $O$ for certain is given by $\Lambda_{\mu}[\widetilde{u}(L, \boldsymbol{\theta})-\widetilde{u}(O, \boldsymbol{\theta})]$, where $\Lambda_{\mu}[x]=1 /(1+\exp (-x / \mu))$ is the cdf of the logistic distribution and $\widetilde{u}()=.\log u($.$) .$

Notice that in this model utility scale is determined up to a multiplication by a positive constant (Luce and Suppes, 1965, p 335). All decision theories that we consider in section 2 except for risk neutrality and Yaari's dual model (which do not have utility function) employ utility functions that are unique up to affine transformation i.e. if utility function $u($.$) represents individual preferences then utility function u^{\prime}()=.a u()+$. 
represents the same preferences for any $a>0$ and any $b$. A decision theory with utility function which is determined up to affine transformation cannot be estimated in conjunction with Luce choice model. If we estimate such decision theory with utility function $u($.$) embedded in Luce choice model, we receive different results compared to$ the estimation of the same decision theory with utility function $u^{\prime}()=.a u()+b,. a>0$, $b \neq 0$. In other words, arbitrary normalization of utility function (in particular, a shift in the utility scale by a constant $b \neq 0)$ affects the estimated parameters of decision theory. Therefore, we do not estimate decision theories embedded in Luce choice model.

\section{Decision Theories}

In contrast to the small number of models of stochastic choice, the number of decision theories reaches well into double-digit figures (Starmer, 2000). In this paper we selected only those decision theories that have a parsimonious parametric form. Specifically, we require that the number of parameters in every decision theory does not exceed two. Nearly all popular decision theories fulfill this requirement and they are briefly described below. However, inevitably, some decision theories are left out. In particular, we do not estimate weighted utility theory (e.g. Chew and McCrimmon, 1979; Chew, 1983) and (cumulative) prospect theory (e.g. Tversky and Kahneman, 1992).

\subsection{Risk Neutrality (RN)}

Risk neutrality is the simplest decision theory. A risk neutral individual always prefers the lottery with the highest expected value of possible outcomes. Formally, under risk neutrality, the utility of a risky lottery $L\left(x_{1}, p_{1} ; \ldots ; x_{n}, p_{n}\right)$ that delivers outcome $x_{i}$ with probability $p_{i}, i \in\{1, \ldots, n\}$, is given by $\sum_{i=1}^{n} p_{i} x_{i}$. There are no free parameters to be estimated for this decision theory, i.e. vector $\boldsymbol{\theta}$ is the empty set. 


\subsection{Expected Utility Theory (EUT)}

According to expected utility theory, an individual evaluates monetary outcomes by means of a subjective utility function and chooses the lottery with the highest expected utility of possible outcomes. Formally, the utility of lottery $L\left(x_{1}, p_{1} ; \ldots ; x_{n}, p_{n}\right)$ is given by $\sum_{i=1}^{n} p_{i} u\left(x_{i}\right)$, where $u: \mathrm{R} \rightarrow \mathrm{R}$ is a (Bernoulli) utility function over money. We will estimate expected utility theory with two utility functions: constant relative risk aversion (CRRA) and expo-power (EP). CRRA utility function is given by $u(x)=x^{1-r} /(1-r)$, when $r \neq 1$, and $u(x)=\log (x)$, when $r=1$. Notice that an individual with CRRA utility function is risk-seeking when $r<0$ and risk-averse when $r>0$. When we restrict $r=0$, EUT with CRRA utility function coincides with RN. For EUT with CRRA utility function, vector $\boldsymbol{\theta}$ consists only of one element - a coefficient of relative risk aversion $r$. EP utility function is given by $u(x)=\frac{1-e^{-\alpha \cdot x^{1-r} /(1-r)}}{\alpha}$, where $\alpha \neq 0$. When $r=0$, EP utility function exhibits a constant coefficient of absolute risk aversion e.g. $-u^{\prime \prime}(x) / u^{\prime}(x)=\alpha$. In the limiting case when $\alpha \rightarrow 0$, EP utility function exhibits a constant coefficient of relative risk aversion i.e. $\lim _{\alpha \rightarrow 0}-\frac{x u^{\prime \prime}(x)}{u^{\prime}(x)}=r$. However, since EP utility function is not defined when $\alpha=0$, it does not nest EUT with CRRA utility function or RN as special cases. For EUT with EP utility function, vector $\boldsymbol{\theta}$ is given by $\boldsymbol{\theta}=[r, \alpha]$. When estimating EUT with EP utility function embedded into a random utility model, we assume that coefficient $r$ is stochastic and coefficient $\alpha$ is deterministic. 


\subsection{Regret Theory (RT) and Skew-Symmetric Bilinear Utility Theory (SSB)}

According to skew-symmetric bilinear utility theory (e.g. Fishburn, 1983), an individual chooses a risky lottery $L\left(x_{1}, p_{1} ; \ldots ; x_{n}, p_{n}\right)$ over a sure monetary amount $O$ if $\Psi(L, O) \equiv \sum_{i=1}^{n} p_{i} \psi\left(x_{i}, O\right) \geq 0$, where $\psi: \mathrm{R} \times \mathrm{R} \rightarrow \mathrm{R}$ is a skew-symmetric function i.e. $\psi(x, O)=-\psi(O, x)$. SSB coincides with regret theory (e.g. Loomes et al., 1992) if $\psi(\cdot, \cdot)$ is convex (the assumption of regret aversion). We will estimate RT (SSB) with function

$$
\psi(x, O)=\left\{\begin{array}{cc}
\left(x^{1-r} /(1-r)-O^{1-r} /(1-r)\right)^{\delta}, & x \geq O \\
-\left(O^{1-r} /(1-r)-x^{1-r} /(1-r)\right)^{\delta}, & x<O
\end{array}\right.
$$

for $r \neq 1, \delta>0$ and function

$$
\psi(x, O)=\left\{\begin{array}{cc}
(\log (x / O))^{\delta}, & x \geq O \\
-(\log (O / x))^{\delta}, & x<O
\end{array}\right.
$$

for $r=1, \delta>0$. This function satisfies the assumption of regret aversion when $\delta>1$.

When we restrict $\delta=1$, RT (SSB) coincides with EUT with CRRA utility function. Interestingly, when we restrict $r=0$, RT (SSB) becomes a restricted version of (cumulative) prospect theory (e.g. Tversky and Kahneman, 1992) with a reference point equal to a sure monetary amount, ${ }^{2}$ no loss aversion ${ }^{3}$ and a linear probability weighting function. Finally, when we restrict $\delta=1$ and $r=0$, RT (SSB) coincides with RN.

Log-likelihood functions for RT (SSB) embedded into different models of stochastic choice are the same as the log-likelihood functions described in section 1 if we replace $u\left(L_{i}, \boldsymbol{\theta}\right)-u\left(O_{i}, \boldsymbol{\theta}\right)$ with $\Psi\left(L_{i}, O_{i}, \boldsymbol{\theta}\right)$ and $u\left(\bar{x}_{i}, \boldsymbol{\theta}\right)-u\left(\underline{x}_{i}, \boldsymbol{\theta}\right)$ with $\psi\left(\bar{x}_{i}, \underline{x}_{i}, \boldsymbol{\theta}\right)$. For

\footnotetext{
${ }^{2}$ Post et al. (2006) argue that a sure monetary amount is a "natural" reference point in binary choice problems where an individual has to decide between a risky lottery and an amount for certain.

${ }^{3}$ Blavatskyy and Pogrebna (2006) find no evidence of loss aversion in the Italian and British versions of Deal or No Deal based on a non-parametric between-subject test.
} 
RT (SSB), parameter vector $\boldsymbol{\theta}$ has two elements: $\boldsymbol{\theta}=[r, \delta]$. When estimating RT (SSB) embedded into a random utility model, we assume that coefficient $r$ is stochastic and coefficient $\delta$ is deterministic.

\subsection{Yaari's Dual Model (YDM)}

According to Yaari's dual model, the utility of a risky lottery $L\left(x_{1}, p_{1} ; \ldots ; x_{n}, p_{n}\right)$, $x_{1}>x_{2}>\ldots>x_{n}$, is given by $\sum_{i=1}^{n}\left[w\left(\sum_{j=1}^{i} p_{j}\right)-w\left(\sum_{j=1}^{i-1} p_{j}\right)\right] \cdot x_{i}$, where $w:[0,1] \rightarrow[0,1]$ is a probability weighting function (e.g. Yaari, 1987). The probability weighting function is strictly increasing and $w(0)=0, w(1)=1$. We will estimate Yaari's dual model with probability weighting function $w(p)=p^{\gamma} /\left(p^{\gamma}+(1-p)^{\gamma}\right)^{1 / \gamma}$. Notice that when $\gamma<1$, this probability weighing function has a typical inverse S-shape i.e. small probabilities $(p<1 / 3)$ of extreme outcomes are overweighted and medium and large probabilities $(p>1 / 3)$ are underweighted (compared to their objective values). When $\gamma>1$, the probability weighting function has atypical S-shape and small probabilities of extreme outcomes are underweighted and medium and large probabilities are overweighted. When we restrict $\gamma=1$, YDM coincides with RN. For YDM, the vector $\boldsymbol{\theta}$ consists only of one element - the coefficient of the probability weighting function $\gamma$.

\subsection{Rank-Dependent Expected Utility Theory (RDEU)}

According to rank-dependent expected utility theory, the utility of a risky lottery $L\left(x_{1}, p_{1} ; \ldots ; x_{n}, p_{n}\right), x_{1}>x_{2}>\ldots>x_{n}$, is given by $\sum_{i=1}^{n}\left[w\left(\sum_{j=1}^{i} p_{j}\right)-w\left(\sum_{j=1}^{i-1} p_{j}\right)\right] \cdot u\left(x_{i}\right)$, where $w:[0,1] \rightarrow[0,1]$ is a probability weighting function and $u: R \rightarrow R$ is utility 
function (e.g. Quiggin, 1981). If all lottery outcomes $x_{1}>x_{2}>\ldots>x_{n}$ are above the reference point of an individual, the prediction of RDEU is identical to the prediction of cumulative prospect theory (e.g. Tversky and Kahneman, 1992). We will estimate RDEU with the probability weighting function $w(p)=p^{\gamma} /\left(p^{\gamma}+(1-p)^{\gamma}\right)^{1 / \gamma}$ and CRRA utility function $u(x)=x^{1-r} /(1-r)$, when $r \neq 1$, and $u(x)=\log (x)$, when $r=1.4$

When we restrict $\gamma=1$, RDEU coincides with EUT with CRRA utility function. When we restrict $r=0$, RDEU coincides with YDM. Finally, when we restrict $\gamma=1$ and $r=0$, RDEU coincides with RN (a total of two restrictions). For RDEU, vector $\boldsymbol{\theta}$ has two elements: $\boldsymbol{\theta}=[r, \gamma]$. When estimating RDEU embedded into a random utility model, we assume that coefficient $r$ is stochastic and coefficient $\gamma$ is deterministic.

\subsection{Disappointment Aversion Theory (DAT)}

According to disappointment aversion theory, an individual experiences disappointment (elation) when a realized outcome of a lottery is below (above) its certainty equivalent. Ex ante, an individual anticipates future disappointment or elation and attempts to minimize ex post disappointment (e.g. Gul, 1991). Formally, the utility of a risky lottery $L\left(x_{1}, p_{1} ; \ldots ; x_{n}, p_{n}\right), \quad x_{1}>x_{2}>\ldots>x_{n}$, is (implicitly) defined by $\frac{1}{1+\beta \sum_{i=n-m+1}^{n} p_{i}} \sum_{i=1}^{n-m} p_{i} u\left(x_{i}\right)+\frac{1+\beta}{1+\beta \sum_{i=n-m+1}^{n} p_{i}} \sum_{i=n-m+1}^{n} p_{i} u\left(x_{i}\right)$, where $m \in\{1, \ldots, n-1\}$ is a number of disappointing outcomes in lottery $L$ and $\beta>-1$ is a subjective parameter that captures disappointment preferences (positive values of $\beta$ indicate disappointment aversion).

\footnotetext{
${ }^{4}$ Notice that RDEU is often estimated with power utility function $u(x)=x^{\alpha}$. By setting $\alpha=1-r$ we can immediately relate our estimates of coefficient $r$ to the estimates of power coefficient $\alpha$, that are often reported in other studies.
} 
We estimate DAT with CRRA utility function $u(x)=x^{1-r} /(1-r)$, when $r \neq 1$, and $u(x)=\log (x)$, when $r=1$. When we restrict $\beta=0$, DAT becomes EUT with CRRA utility function. When we restrict $\beta=0$ and $r=0$, DAT coincides with RN. For DAT, vector $\boldsymbol{\theta}=[r, \beta]$. When estimating DAT embedded into a random utility model, we assume that coefficient $r$ is stochastic and coefficient $\beta$ is deterministic.

\section{Data}

We use data from a natural experiment provided by the television show Deal or No Deal. In this show, monetary prizes ranging from one cent to half-a-million are randomly allocated across identical boxes. The list of potential prizes is common knowledge but their allocation across boxes is kept secret. A contestant is endowed with one box and she has to open the remaining boxes one by one. Once a box is opened, the prize sealed inside is publicly revealed and deleted from the list of possible prizes.

The more boxes are opened, the more information the contestant receives about the distribution of possible prizes inside her box. After opening several boxes the contestant receives an offer from the "bank" (the timing of "bank" offers is presented on Figure 1 and Figure 2 in the Appendix). The "bank" offers either a sure monetary amount in exchange for the contestant's box or the possibility to swap the contestant's box for any of the remaining unopened boxes. If the contestant rejects the sure amount, and regardless of the contestant's decision on the swap offer, she has to continue opening boxes one by one until the "bank" makes another offer or all boxes are opened.

Monetary offers are fairly predictable across episodes and follow a general pattern. When many boxes remain unopened, the "bank" offers amounts significantly below the expected value of possible prizes. As more and more boxes are opened, the gap between the 
expected value of remaining prizes and a monetary offer decreases. The game terminates either when the contestant accepts a sure monetary amount or when all boxes are opened. In the latter case, the contestant leaves with the content of her box, which is opened last.

Our dataset consists of 114 episodes of the Italian version of the show (Affari Tuoi) broadcasted on the first channel of Italian television RAI Uno from September 20, 2005 to March 4, 2006 and 275 episodes of the British version of the show (Deal or No Deal UK) aired on Channel 4 of the British television from October 31, 2005 to October $13,2006^{5}$. In every episode, only one contestant plays the game and she decides on at least one monetary offer. ${ }^{6}$ The variables that we use in the empirical estimation are the contestant's decision to accept or to reject an offer and the distribution of possible prizes that the contestant can potentially win at the moment when she makes each decision.

$45.6 \%$ of Italian contestants and $50.2 \%$ of British contestants are male. Average age is 46.3 years for the Italian contestants and 41 years for the British contestants. $14.0 \%$ and $78.9 \%$ of Italian contestants and $48.3 \%$ and $50.8 \%$ of British contestants are correspondingly single and married. Representatives of all administrative regions of Italy and representatives of 22 administrative regions of the United Kingdom appear in our recorded dataset. Thus, this natural experiment employs a more representative subject pool than conventional pools, composed primarily of undergraduate students.

Ex ante expected value of monetary prizes that are allocated across boxes is $€ 52,295$ in Affari Tuoi and £25,712 in Deal or No Deal UK. Average and median

\footnotetext{
${ }^{5}$ Blavatskyy and Pogrebna (2007) and Pogrebna (2007) describe in detail television shows Affari Tuoi and Deal or No Deal UK. Blavatskyy and Pogrebna (2007) also provide a detailed review of numerous working papers that analyze data from different national versions of the television show Deal or No Deal. "In our recorded sample only one Affari Tuoi contestant accepted the first monetary offer from the "bank" $(€ 18,000)$. Ten contestants accepted the second monetary offer that they received from the "bank". 34 contestants accepted their third monetary offer. All remaining contestants received from 4 to 7 monetary offers. In Deal or No Deal UK all contestants rejected the first two monetary offers, 9 contestants accepted the third monetary offer and all remaining contestants received from 4 to 7 monetary offers.
} 
earnings of Italian contestants are $€ 29,516$ and $€ 19,000$ respectively. Average and median earnings of British contestants are $£ 16,069$ and $£ 13,000$ correspondingly. Overall, obtaining a similar dataset in conventional laboratory conditions would be a highly ambitious project, since it would require a total budget of almost 10 million euros.

The natural experiment allows us to use a more representative subject pool and significantly higher incentives than in a typical laboratory experiment. However, it has a disadvantage that we do not have any control over sure amounts that are offered to the contestants. Moreover, a precise mechanism of setting "bank" offers is not revealed to the public in official show regulations. Table 1 and Table 2 show that the variability in "bank" monetary offers is largely explained by only one variable — the expected value of possible prizes (particularly when few boxes remain unopened). We also regressed "bank" monetary offers on other lottery-specific variables (a median possible prize, the standard deviation of possible prizes and a prize hidden inside the contestant's box) and socio-demographic characteristics of contestants (gender, age, marital status and region). Among these variables, only regression coefficient on the standard deviation of possible prizes was statistically significant (the more dispersed are the prizes, the lower is the offer). Notably, regression coefficient on the prize inside the contestant's box was never statistically significant, i.e. there is no information content in "bank" offers in our sample.

\begin{tabular}{|r|c|c|c|c|c|c|}
\hline $\begin{array}{l}\text { Number of } \\
\text { unopened boxes }\end{array}$ & $\mathbf{2}$ & $\mathbf{3}$ & $\mathbf{4}$ & $\mathbf{5}$ & $\mathbf{8}$ & $\mathbf{1 1}$ \\
\hline Constant $\hat{\beta}_{0}$ & -0.9796 & -3.0064 & 0.6209 & 0.6610 & -0.5971 & -5.2172 \\
\hline Expected value $\hat{\beta}_{1}$ & 1.0572 & 1.1960 & 0.8479 & 0.8395 & 0.9308 & 1.3314 \\
\hline $\mathbf{R}^{2}$ & 0.9285 & 0.8725 & 0.9829 & 0.8870 & 0.7216 & 0.6555 \\
\hline \multicolumn{1}{|c|}{ Observations } & 41 & 11 & 13 & 96 & 111 & 114 \\
\hline
\end{tabular}

Table 1 Ordinary least squares regression $\ln \mathbf{O}=\beta_{0}+\beta_{1} \ln \mathbf{E V}+\boldsymbol{\varepsilon}$ of "bank" monetary offers $\mathrm{O}$ on expected value $\mathrm{EV}$ of possible prizes in Affari Tuoi 


\begin{tabular}{|l|c|c|c|c|c|c|}
\hline $\begin{array}{l}\text { Number of } \\
\text { unopened boxes }\end{array}$ & $\mathbf{2}$ & $\mathbf{5}$ & $\mathbf{8}$ & $\mathbf{1 1}$ & $\mathbf{1 4}$ & $\mathbf{1 7}$ \\
\hline Constant $\hat{\beta}_{0}$ & -0.3603 & -0.8851 & -1.1097 & -2.7589 & -6.7005 & -13.9471 \\
\hline Expected value $\hat{\beta}_{1}$ & 0.9995 & 1.0206 & 1.0201 & 1.1627 & 1.5142 & 2.1725 \\
\hline $\mathbf{R}^{2}$ & 0.9909 & 0.8992 & 0.7429 & 0.5729 & 0.3853 & 0.3300 \\
\hline Observations & 114 & 202 & 264 & 275 & 275 & 269 \\
\hline
\end{tabular}

Table 2 Ordinary least squares regression $\ln \mathbf{O}=\beta_{0}+\beta_{1} \ln \mathbf{E V}+\boldsymbol{\varepsilon}$ of "bank" monetary offers $O$ on expected value EV of possible prizes in Deal or No Deal UK

\section{Results}

In Deal or No Deal television show contestants face a series of binary choices between a degenerate lottery ("bank" monetary offer for certain) and a risky lottery. We will consider first a static case when contestants evaluate a risky lottery as a lottery that delivers each of the possible prizes (that have not yet been eliminated from the game) with equal probability. Then we will consider a dynamic case, when contestants evaluate a risky lottery taking into account the expectation of future "bank" offers that they will receive if they reject the current offer.

Since every contestant makes only up to 7 decisions, we adopt a representative agent approach and estimate every pair of decision theory and stochastic choice model on the aggregate data. The utility of lotteries is evaluated through the parametric form of decision theories described in section 2. The free parameters of decision theories are estimated by maximizing the log-likelihood function of a selected model of stochastic choice described in section 1. Non-linear unconstrained optimization was implemented in the Matlab 7.2 package (based on the Nelder-Mead simplex algorithm). 


\subsection{Static decision problem}

In a static decision problem, a contestant facing prizes $x_{1}, \ldots, x_{n}$ hidden in $n$ unopened boxes perceives them as a risky lottery $L\left(x_{1}, 1 / n ; \ldots ; x_{n}, 1 / n\right)$. In other words, the contestant behaves as if after rejecting a current "bank" offer she receives each of the remaining prizes with equal probability. Table 3 shows maximum likelihood estimates of the parameters of decision theories embedded in five different models of stochastic choice and a corresponding log-likelihood of observing actual decisions of Affari Tuoi contestants. A comparison of parameter estimates of the same decision theory across different columns of Table 3 demonstrates our first somewhat unexpected result:

\section{Result 1 Estimated parameters of the same decision theory differ substantially, depending on which model of stochastic choice the theory is embedded in.}

For example, estimates of EUT with CRRA utility function indicate risk neutrality in a tremble model, risk aversion - in a Fechner model, and risk seeking (on average) - in a random utility model. Estimates of DAT indicate disappointment neutrality in a tremble model, strong disappointment seeking - in a Fechner model with homoscedastic and heteroscedastic errors and slight disappointment aversion—in the remaining models.

Estimates of EUT with EP utility function show that $r<0$ and $\alpha>0$ for all models except for a tremble model i.e. contestants exhibit increasing relative risk aversion and increasing absolute risk aversion. Estimates of RT (SSB) are consistent with the assumption of regret aversion only in a Fechner model with heteroscedastic errors and in a random utility model. Estimates of YDM show no probability distortions in a tremble model, overweighting of small probabilities - in a Fechner model with homoscedastic and heteroscedastic errors, and underweighting of small probabilities - in the remaining 
models of stochastic choice. Under RDEU, the utility function is estimated to be linear in a tremble model, concave - in a Fechner model, and convex (on average) - in a random utility model.

\begin{tabular}{|c|c|c|c|c|c|}
\hline \multirow{2}{*}{ Decision theory } & \multirow[b]{2}{*}{ Tremble } & \multicolumn{3}{|c|}{ Fechner model of random errors } & \multirow[b]{2}{*}{$\begin{array}{c}\text { Random } \\
\text { utility }\end{array}$} \\
\hline & & $\begin{array}{c}\text { Homo- } \\
\text { scedastic }\end{array}$ & $\begin{array}{l}\text { Hetero- } \\
\text { scedastic }\end{array}$ & \begin{tabular}{|c|} 
Hetero- \\
scedastic \& \\
truncated
\end{tabular} & \\
\hline $\mathbf{R N}$ & $\begin{array}{l}p=0.1603 \\
L L=-179.2\end{array}$ & $\begin{array}{l}\sigma=68685 \\
L L=-225.8\end{array}$ & $\begin{array}{l}\sigma=0.1698 \\
L L=-196.8\end{array}$ & $\begin{array}{l}\sigma=0.3267 \\
L L=-174.2\end{array}$ & $L L=-\infty$ \\
\hline EUT + CRRA & $\begin{array}{l}p=0.1603 \\
r=0 \\
L L=-179.2\end{array}$ & $\begin{array}{l}\sigma=328.4 \\
r=0.4004 \\
L L=-206.0\end{array}$ & $\begin{array}{l}\sigma=0.1413 \\
r=0.1928 \\
L L=-193.1\end{array}$ & $\begin{array}{l}\sigma=4.0367 \\
r=0.2894 \\
L L=-165.8\end{array}$ & $\begin{array}{l}\mu=-0.2664 \\
\sigma=0.8619 \\
L L=-174.3\end{array}$ \\
\hline $\mathbf{E U T}+\mathbf{E P}$ & $\begin{array}{l}p=0.1065 \\
r=-0.3389 \\
\alpha=-0.0013 \\
L L=-168.9\end{array}$ & $\begin{array}{l}\sigma=10293 \\
r=-0.0199 \\
\alpha=8.2 * 10^{-6} \\
L L=-176.9\end{array}$ & $\begin{array}{l}\sigma=0.1229 \\
r=-0.0639 \\
\alpha=4.9 * 10^{-6} \\
L L=-175.1\end{array}$ & $\begin{array}{l}\sigma=2.7150 \\
r=-0.1442 \\
\alpha=2.2 * 10^{-6} \\
L L=-157.3\end{array}$ & $\begin{array}{l}\mu=-0.6227 \\
\sigma=1.1254 \\
\alpha=2.6^{*} 10^{-9} \\
L L=-172.6\end{array}$ \\
\hline RT (SSB) & $\begin{array}{l}p=0.1603 \\
r=0 \\
\delta=1 \\
L L=-179.2\end{array}$ & $\begin{array}{l}\sigma=103.573 \\
r=0.2147 \\
\delta=0.6707 \\
L L=-204.09\end{array}$ & $\begin{array}{l}\sigma=0.1401 \\
r=0.2107 \\
\delta=1.0549 \\
L L=-193.1\end{array}$ & $\begin{array}{l}\sigma=3.8392 \\
r=-0.3929 \\
\delta=0.3876 \\
L L=-163.6\end{array}$ & $\begin{array}{l}\mu=0.0130 \\
\sigma=0.7210 \\
\delta=19.0623 \\
L L=-172.4\end{array}$ \\
\hline YDM & $\begin{array}{l}p=0.1603 \\
\gamma=1 \\
L L=-179.2\end{array}$ & $\begin{array}{l}\sigma=40628 \\
\gamma=0.3151 \\
L L=-202.6\end{array}$ & $\begin{array}{l}\sigma=0.1804 \\
\gamma=0.5302 \\
L L=-177.9\end{array}$ & $\begin{array}{l}\sigma=0.3295 \\
\gamma=1.9753 \\
L L=-168.1\end{array}$ & $\begin{array}{l}\mu=2.3419 \\
\sigma=2.0457 \\
L L=-178.1\end{array}$ \\
\hline RDEU & $\begin{array}{l}p=0.1603 \\
r=0 \\
\gamma=1 \\
L L=-179.2\end{array}$ & $\begin{array}{l}\sigma=273.7 \\
r=0.4262 \\
\gamma=0.5986 \\
L L=-193.3\end{array}$ & $\begin{array}{l}\sigma=0.1747 \\
r=0.0727 \\
\gamma=0.5572 \\
L L=-177.8\end{array}$ & $\begin{array}{l}\sigma=0.9782 \\
r=0.2589 \\
\gamma=1.5697 \\
L L=-165.8\end{array}$ & $\begin{array}{l}\mu=-0.2498 \\
\sigma=0.8576 \\
\gamma=0.8264 \\
L L=-173.5\end{array}$ \\
\hline DAT & $\begin{array}{l}p=0.1603 \\
r=0 \\
\beta=0 \\
L L=-179.2\end{array}$ & $\begin{array}{l}\sigma=2.4008 \\
r=1.0088 \\
\beta=-0.9999 \\
L L=-167.1\end{array}$ & $\begin{array}{l}\sigma=0.6139 \\
r=0.6280 \\
\beta=-0.9999 \\
L L=-169.6\end{array}$ & $\begin{array}{l}\sigma=3.6060 \\
r=0.2890 \\
\beta=0.0960 \\
L L=-165.8\end{array}$ & $\begin{array}{l}\mu=-0.2750 \\
\sigma=0.8612 \\
\beta=0.0226 \\
L L=-173.9\end{array}$ \\
\hline
\end{tabular}

Table 3 Maximum likelihood estimates of parameters of decision theories embedded in different models of stochastic choice and obtained log-likelihood values (data from Affari Tuoi, static decision problem)

The estimated coefficient of the probability weighting function in RDEU embedded in a Fechner model with heteroscedastic truncated errors is significantly higher than one, which indicates that the probability weighting function is S-shaped and convex 
nearly on its entire domain. This unexpected result incurs in all subsequent estimations and it is worthwhile to explain its cause. In a Fechner model with heteroscedastic truncated errors, random errors are likely to increase utility of lotteries that deliver improbable gains and the same random errors are likely to decrease utility of lotteries that deliver probable gains (e.g. Blavatskyy, 2007). Traditional inverse S-shaped probability weighting function of RDEU fulfils exactly the same role.

RDEU embedded in a Fechner model with heteroscedastic truncated errors has two built-in components that both can lead to systematic overweighting of small probabilities and underweighting of large probabilities. In a maximum likelihood estimation of such model, there is no need to keep both components at work. If the estimated standard deviation of random errors converges to zero, the systematic effect of random errors disappears. If the estimated coefficient of the probability weighting function gets larger than one, traditional effect of probability distortions disappears. Clearly, Table 3 shows that the second possibility yields better fit to the data.

To compare the fit of various combinations of a decision theory with a model of stochastic choice, we use a likelihood ratio test for nested models and Vuong likelihood ratio test for non-nested models (e.g. Vuong, 1989). Loomes et al. (2002, p.128) describe application of Vuong non-nested likelihood ratio test to the selection between different stochastic choice models. To compare the goodness of fit of non-nested models, we also use Clarke test (Clarke, 2003), which is a paired sign test on the log-likelihoods of every data point. The results of Vuong and Clarke tests turn out to be qualitatively similar. However, Clarke test is more discriminatory-for several non-nested models Vuong test shows no significant difference in their goodness of fit, while Clarke test indicates that one of the models is closer to the true data generating process. In the remainder of this 
paper we report conclusions based on Vuong test and we mention instances when Clarke test yields stronger results. ${ }^{6}$ Our second important result can be summarized as follows.

\section{Result 2 For every decision theory, the best fit to the data is obtained when this theory is embedded into a Fechner model with heteroscedastic truncated errors.}

Perhaps not surprisingly, for every model of stochastic choice but a tremble model, the worst fit to the data is obtained when this model is combined with RN. However, there is no single decision theory that provides the best goodness of fit in all models.

\section{Result 3 Which decision theory provides the best goodness of fit depends on the selected model of stochastic choice. For example, it is EUT with EP utility function in a tremble model, DAT — in a Fechner model of homoscedastic errors, and either EUT with EP utility function or RDEU-in a Fechner model of heteroscedastic truncated errors.}

Result 3 implies that any comparison of decision theories should be always reported with a reference to the model of stochastic choice that is being used. Otherwise, a hunter for a descriptive decision theory would claim that DAT performs better than other theories in a Fechner model with homoscedastic and heteroscedastic errors. A researcher who employs a Fechner model with heteroscedastic truncated errors or a tremble model would claim that EUT with EP utility function performs better than other theories. At the same time a researcher who uses a random utility model would conclude that EUT, RDEU and DAT perform better than other theories.

Table 4 shows the estimated parameters of decision theories embedded into different models of stochastic choice and a corresponding log-likelihood of the decisions of Deal or No Deal UK contestants. Result 1 is clearly confirmed in Table 4. For

\footnotetext{
${ }^{6}$ The results of Clarke test are not reported in this paper but they are available from the authors on request.
} 
example, when YDM is incorporated into a Fechner model with homoscedastic or heteroscedastic errors, estimated probability weighting function has an inverse S-shape $(\gamma<1)$, but it has S-shape $(\gamma>1)$ when YDM is incorporated in other models.

\begin{tabular}{|c|c|c|c|c|c|}
\hline \multirow{2}{*}{ Decision theory } & \multirow[b]{2}{*}{ Tremble } & \multicolumn{3}{|c|}{ Fechner model of random errors } & \multirow[b]{2}{*}{$\begin{array}{c}\text { Random } \\
\text { utility }\end{array}$} \\
\hline & & $\begin{array}{l}\text { Homo- } \\
\text { scedastic }\end{array}$ & $\begin{array}{l}\text { Hetero- } \\
\text { scedastic }\end{array}$ & $\begin{array}{c}\text { Hetero- } \\
\text { scedastic \& } \\
\text { truncated }\end{array}$ & \\
\hline \multirow{2}{*}{$\mathbf{R N}$} & & $\sigma=17767$ & $\sigma=0.1144$ & & \multirow[b]{2}{*}{$L L=-\infty$} \\
\hline & & $L L=-638.5$ & $L L=-610.6$ & $L L=-462.7$ & \\
\hline EUT + CRRA & $\begin{array}{l}p=0.1365 \\
r=0.2506 \\
L L=-557.7\end{array}$ & $\begin{array}{l}\sigma=336.97 \\
r=0.3098 \\
L L=-545.8\end{array}$ & $\begin{array}{l}\sigma=0.0719 \\
r=0.2710 \\
L L=-537.7\end{array}$ & $\begin{array}{l}\sigma=0.5043 \\
r=0.1294 \\
L L=-458.5\end{array}$ & $\begin{array}{l}\mu=0.1774 \\
\sigma=0.2981 \\
L L=-478.5 \\
\end{array}$ \\
\hline $\mathbf{E U T}+\mathbf{E P}$ & $\begin{array}{l}p=0.0844 \\
r=-0.3849 \\
\alpha=-0.00156 \\
L L=-510.1\end{array}$ & $\begin{array}{l}\sigma=4127.7 \\
r=0.0229 \\
\alpha=1.2 * 10^{-5} \\
L L=-505.9\end{array}$ & $\begin{array}{l}\sigma=0.0762 \\
r=0.1489 \\
\alpha=2.9 * 10^{-5} \\
L L=-522.9\end{array}$ & $\begin{array}{l}\sigma=1.1347 \\
r=-0.1737 \\
\alpha=2.6^{*} 10^{-6} \\
L L=-441.1\end{array}$ & $\begin{array}{l}\mu=-0.0972 \\
\sigma=0.5520 \\
\alpha=3.6^{*} 10^{-9} \\
L L=-517.7\end{array}$ \\
\hline RT (SSB) & $\begin{array}{l}p=0.1337 \\
r=0.2974 \\
\delta=1.2107 \\
L L=-550.2\end{array}$ & $\begin{array}{l}\sigma=729.89 \\
r=0.3877 \\
\delta=1.2135 \\
L L=-542.6\end{array}$ & $\begin{array}{l}\sigma=0.0668 \\
r=0.3546 \\
\delta=1.3264 \\
L L=-527.9\end{array}$ & $\begin{array}{l}\sigma=0.2992 \\
r=0.2726 \\
\delta=1.7111 \\
L L=-455.9\end{array}$ & $\begin{array}{l}\mu=0.3229 \\
\sigma=0.2462 \\
\delta=1.6046 \\
L L=-467.6\end{array}$ \\
\hline YDM & $\begin{array}{l}p=0.1422 \\
\gamma=1.3582 \\
L L=-572.2\end{array}$ & $\begin{array}{l}\sigma=13425 \\
\gamma=0.3151 \\
L L=-543.0\end{array}$ & $\begin{array}{l}\sigma=0.1165 \\
\gamma=0.4512 \\
L L=-484.7\end{array}$ & $\begin{array}{l}\sigma=0.3994 \\
\gamma=2.5381 \\
L L=-447.4\end{array}$ & $\begin{array}{l}\mu=1.8238 \\
\sigma=1.2214 \\
L L=-513.7\end{array}$ \\
\hline RDEU & $\begin{array}{l}p=0.1287 \\
r=0.3159 \\
\gamma=0.6706 \\
L L=-537.0\end{array}$ & $\begin{array}{l}\sigma=169.57 \\
r=0.3875 \\
\gamma=0.6150 \\
L L=-486.0\end{array}$ & $\begin{array}{l}\sigma=0.0883 \\
r=0.2887 \\
\gamma=0.6286 \\
L L=-460.4\end{array}$ & $\begin{array}{l}\sigma=0.1922 \\
r=-0.3037 \\
\gamma=2.4558 \\
L L=-440.0\end{array}$ & $\begin{array}{l}\mu=0.2466 \\
\sigma=0.2672 \\
\gamma=0.7849 \\
L L=-462.6\end{array}$ \\
\hline DAT & $\begin{array}{l}p=0.1351 \\
r=0.0012 \\
\beta=0.5497 \\
L L=-553.9\end{array}$ & $\begin{array}{l}\sigma=1.2772 \\
r=0.9656 \\
\beta=-0.9265 \\
L L=-473.8\end{array}$ & $\begin{array}{l}\sigma=0.4462 \\
r=0.7378 \\
\beta=-0.9999 \\
L L=-506.0\end{array}$ & $\begin{array}{l}\sigma=0.2187 \\
r=-0.1776 \\
\beta=1.6644 \\
L L=-445.7\end{array}$ & $\begin{array}{l}\mu=0.1403 \\
\sigma=0.3073 \\
\beta=0.1113 \\
L L=-472.6\end{array}$ \\
\hline
\end{tabular}

Table 4 Maximum likelihood estimates of parameters of decision theories embedded in different models of stochastic choice and obtained log-likelihood values (data from Deal or No Deal UK, static decision problem)

Maximum likelihood estimate of EUT with CRRA utility function shows that Deal or No Deal UK contestants are slightly risk averse (with a coefficient of relative risk aversion being between 0.13 and 0.31). Maximum likelihood estimate of EUT with EP 
utility function shows that contestants exhibit increasing relative risk aversion $(\alpha>0)$ in all models except for a tremble model. They also reveal decreasing absolute risk aversion $(r>0)$ in a Fechner model with homoscedastic or heteroscedastic errors. However, contestants exhibit increasing absolute risk aversion $(r<0)$ in the remaining models.

Maximum likelihood estimate of RDEU shows that Deal or No Deal UK contestants have an inverse S-shaped probability weighting function (with coefficient $\gamma$ being between 0.61 and 0.79 ) and a concave utility function (with a coefficient of relative risk aversion being between 0.24 and 0.39 ) in all models except for a Fechner model with heteroscedastic truncated errors. Estimate of DAT shows that contestants are disappointment seeking in a Fechner model with homoscedastic or heteroscedastic errors and disappointment averse - in the remaining models.

Similar as in the Italian dataset, Result 2 holds: every decision theory describes the decisions of Deal or No Deal UK contestants most accurately, when it is embedded in a Fechner model with heteroscedastic truncated errors. For every model of stochastic choice, the worst fit to the data is obtained when this model is combined with RN. Table 5 compares the goodness of fit of selected pairs of a decision theory and a stochastic choice model (for each model we selected two theories that outperformed other theories embedded in the same stochastic choice model). Result 3 clearly holds in Table 5 . In a tremble model and a Fechner model with heteroscedastic truncated errors, EUT with EP utility function and RDEU are most successful in describing the decisions of contestants. In a Fechner model with homoscedastic errors, the decisions of Deal or No Deal UK contestants are best predicted by DAT or RDEU. In a Fechner model with heteroscedastic errors and a random utility model, RDEU gives the best fit to the data.

By comparing the goodness of fit across different models of stochastic choice, it is apparent that decision theories embedded in a tremble model perform significantly 
worse compared to theories embedded in other models. Decision theories embedded in a Fechner model with homoscedastic errors yield similar goodness of fit as the theories embedded in a random utility model (Carbone (1997) and Loomes et al. (2002) find similar evidence in laboratory experiments). RDEU embedded into a Fechner model with heteroscedastic errors and RDEU or EUT with EP utility function embedded into a Fechner model with heteroscedastic truncated errors provide the best fit to the data.

\begin{tabular}{|c|c|c|c|c|c|c|c|c|c|c|c|}
\hline \multirow{2}{*}{$\begin{array}{l}\text { Stochastic } \\
\text { Choice } \\
\text { Model } \\
\quad \downarrow\end{array}$} & \multirow{2}{*}{$\begin{array}{c}\rightarrow \\
\begin{array}{c}\text { Decision } \\
\text { Theory }\end{array}\end{array}$} & \multicolumn{2}{|c|}{$\begin{array}{c}\text { Tremble } \\
\text { Model }\end{array}$} & \multicolumn{2}{|c|}{$\begin{array}{c}\text { Fechner model, } \\
\text { homoscedastic } \\
\text { errors }\end{array}$} & \multicolumn{2}{|c|}{$\begin{array}{c}\text { Fechner model, } \\
\text { heteroscedastic } \\
\text { errors } \\
\end{array}$} & \multicolumn{2}{|c|}{$\begin{array}{c}\text { Fechner model, } \\
\text { heteroscedastic } \\
\text { truncated errors }\end{array}$} & \multicolumn{2}{|c|}{$\begin{array}{c}\text { Random } \\
\text { Utility Model }\end{array}$} \\
\hline & & $\begin{array}{c}\text { EUT+ } \\
\text { EP }\end{array}$ & RDEU & DAT & RDEU & RDEU & YDM & RDEU & $\begin{array}{c}\text { EUT+ } \\
\text { EP } \\
\end{array}$ & RDEU & $\begin{array}{c}\text { RT } \\
\text { (SSB) }\end{array}$ \\
\hline \multirow{2}{*}{ 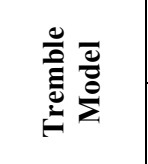 } & $\begin{array}{c}\text { EUT+ } \\
\text { EP }\end{array}$ & & $\begin{array}{c}1.1770 \\
(0.1196)\end{array}$ & $\begin{array}{c}-2.2668 \\
(0.0117)\end{array}$ & $\begin{array}{l}-1.0319 \\
(0.1511)\end{array}$ & $\begin{array}{l}-2.3669 \\
(0.0090)\end{array}$ & \begin{tabular}{|c|}
-1.3135 \\
$(0.0945)$ \\
\end{tabular} & & & & \\
\hline & RDEU & $\begin{array}{l}-1.1770 \\
(0.1196)\end{array}$ & - & $\begin{array}{l}-4.0060 \\
(0.0000)\end{array}$ & $\begin{array}{c}-2.9605 \\
(0.0015)\end{array}$ & $\begin{array}{l}-6.5558 \\
(0.0000)\end{array}$ & \begin{tabular}{|l|}
-4.1938 \\
$(0.0000)$
\end{tabular} & \begin{tabular}{|l|}
-7.3285 \\
$(0.0000)$
\end{tabular} & & & \\
\hline \multirow{2}{*}{ 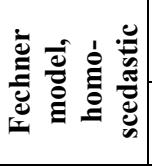 } & DAT & $\begin{array}{c}2.2668 \\
(0.0117) \\
\end{array}$ & $\begin{array}{c}4.0060 \\
(0.0000) \\
\end{array}$ & - & $\begin{array}{c}0.8043 \\
(0.2106)\end{array}$ & $\begin{array}{c}-1.0934 \\
(0.1371)\end{array}$ & $\begin{array}{c}0.8275 \\
(0.2040)\end{array}$ & $\begin{array}{c}-3.4814 \\
(0.0002)\end{array}$ & \begin{tabular}{|l|}
-3.5001 \\
$(0.0002)$ \\
\end{tabular} & $\begin{array}{l}-0.9827 \\
(0.1629)\end{array}$ & \\
\hline & RDEU & $\begin{array}{c}1.0319 \\
(0.1511) \\
\end{array}$ & $\begin{array}{c}2.9605 \\
(0.0015) \\
\end{array}$ & $\begin{array}{l}-0.8043 \\
(0.2106) \\
\end{array}$ & - & $\begin{array}{l}-2.1569 \\
(0.0155)\end{array}$ & $\begin{array}{c}-0.1589 \\
(0.4369)\end{array}$ & $\begin{array}{l}-3.9607 \\
(0.0000)\end{array}$ & & $\begin{array}{l}-1.4736 \\
(0.0703)\end{array}$ & $\begin{array}{l}-1.1885 \\
(0.1173)\end{array}$ \\
\hline \multirow{2}{*}{ 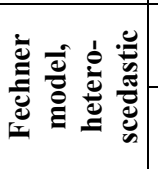 } & RDEU & $\begin{array}{c}2.3669 \\
(0.0090)\end{array}$ & $\begin{array}{c}6.5558 \\
(0.0000)\end{array}$ & $\begin{array}{c}1.0934 \\
(0.1371)\end{array}$ & $\begin{array}{c}2.1569 \\
(0.0155)\end{array}$ & - & $\begin{array}{c}3.3470 \\
(0.0004)\end{array}$ & $\begin{array}{l}-2.3506 \\
(0.0094)\end{array}$ & \begin{tabular}{|l|}
-1.4655 \\
$(0.0714)$ \\
\end{tabular} & $\begin{array}{c}0.2120 \\
(0.4160)\end{array}$ & $\begin{array}{c}0.7536 \\
(0.2256)\end{array}$ \\
\hline & YDM & $\begin{array}{c}1.3135 \\
(0.0945) \\
\end{array}$ & $\begin{array}{c}4.1938 \\
(0.0000)\end{array}$ & \begin{tabular}{|c|}
-0.8275 \\
$(0.2040)$ \\
\end{tabular} & $\begin{array}{c}0.1589 \\
(0.4369) \\
\end{array}$ & $\begin{array}{l}-3.3470 \\
(0.0004)\end{array}$ & - & \begin{tabular}{|c|}
-6.8205 \\
$(0.0000)$
\end{tabular} & \begin{tabular}{|l|}
-3.8375 \\
$(0.0001)$
\end{tabular} & $\begin{array}{l}-1.7646 \\
(0.0388)\end{array}$ & $\begin{array}{l}-1.3467 \\
(0.0890)\end{array}$ \\
\hline \multirow{2}{*}{ 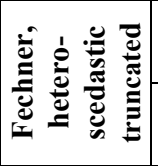 } & RDEU & $\begin{array}{c}4.0456 \\
(0.0000) \\
\end{array}$ & $\begin{array}{c}7.3285 \\
(0.0000) \\
\end{array}$ & $\begin{array}{c}3.4814 \\
(0.0002) \\
\end{array}$ & $\begin{array}{c}3.9607 \\
(0.0000) \\
\end{array}$ & $\begin{array}{c}2.3506 \\
(0.0094) \\
\end{array}$ & \begin{tabular}{|c|}
6.8205 \\
$(0.0000)$ \\
\end{tabular} & - & \begin{tabular}{|c|}
0.1441 \\
$(0.4427)$ \\
\end{tabular} & $\begin{array}{c}1.9521 \\
(0.0255) \\
\end{array}$ & $\begin{array}{c}2.4064 \\
(0.0081) \\
\end{array}$ \\
\hline & $\begin{array}{c}\text { EUT+ } \\
\text { EP }\end{array}$ & $\begin{array}{c}5.8390 \\
(0.0000) \\
\end{array}$ & $\begin{array}{c}5.8528 \\
(0.0000) \\
\end{array}$ & $\begin{array}{c}3.5001 \\
(0.0002) \\
\end{array}$ & $\begin{array}{c}2.7439 \\
(0.0030) \\
\end{array}$ & $\begin{array}{c}1.4655 \\
(0.0714) \\
\end{array}$ & \begin{tabular}{|c|}
3.8375 \\
$(0.0001)$ \\
\end{tabular} & \begin{tabular}{|c|}
-0.1441 \\
$(0.4427)$ \\
\end{tabular} & - & $\begin{array}{c}1.5298 \\
(0.0630) \\
\end{array}$ & $\begin{array}{c}1.9747 \\
(0.0242) \\
\end{array}$ \\
\hline \multirow{2}{*}{ 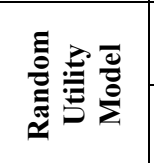 } & RDEU & $\begin{array}{c}2.3357 \\
(0.0098) \\
\end{array}$ & $\begin{array}{c}5.2530 \\
(0.0000) \\
\end{array}$ & $\begin{array}{c}0.9827 \\
(0.1629) \\
\end{array}$ & $\begin{array}{c}1.4736 \\
(0.0703) \\
\end{array}$ & $\begin{array}{c}-0.2120 \\
(0.4160) \\
\end{array}$ & \begin{tabular}{|c|}
1.7646 \\
$(0.0388)$ \\
\end{tabular} & \begin{tabular}{|l|}
-1.9521 \\
$(0.0255)$ \\
\end{tabular} & \begin{tabular}{|c|}
-1.5298 \\
$(0.0630)$ \\
\end{tabular} & & $\begin{array}{c}0.9505 \\
(0.1709) \\
\end{array}$ \\
\hline & $\begin{array}{c}\text { RT } \\
\text { (SSB) }\end{array}$ & $\begin{array}{c}2.1240 \\
(0.0168)\end{array}$ & $\begin{array}{c}4.9651 \\
(0.0000)\end{array}$ & $\begin{array}{c}0.5782 \\
(0.2816) \\
\end{array}$ & $\begin{array}{c}1.1885 \\
(0.1173) \\
\end{array}$ & $\begin{array}{c}-0.7536 \\
(0.2256)\end{array}$ & $\begin{array}{c}1.3467 \\
(0.0890)\end{array}$ & \begin{tabular}{|c|}
-2.4064 \\
$(0.0081)$
\end{tabular} & $\begin{array}{l}-1.9747 \\
(0.0242)\end{array}$ & $\begin{array}{c}-0.9505 \\
(0.1709)\end{array}$ & - \\
\hline
\end{tabular}

Table 5 Vuong non-nested likelihood ratio test ( $p$-value) of selected pairs of a decision theory and a stochastic choice model (Deal or No Deal UK, static problem). A significantly positive (negative) value indicates that a row (column) pair is closer to the true data generating process than a column (row) pair. Akaike Information Criterion is used to adjust for a smaller number of parameters in YDM. 


\subsection{Dynamic decision problem}

In a dynamic decision problem, contestants take into account future offers that the "bank" makes if the current offer is rejected. A contestant facing prizes $x_{1}$ and $x_{2}$ hidden in two unopened boxes perceives them as a risky lottery $L\left(x_{1}, 1 / 2 ; x_{2}, 1 / 2\right)$ just as in a static decision problem. ${ }^{7}$ A contestant facing prizes $\mathbf{x}=\left\{x_{1}, \ldots, x_{n}\right\}$ hidden in $n>2$ unopened boxes perceives them as a risky lottery $L(\mathbf{x})$. Let $m$ denote the number of boxes that the contestant has to open before the next "bank" offer is made ( $m$ is either 1 or 3 in Affari Tuoi and $m=3$ in Deal or No Deal UK). There are $C_{n-m}^{n}=n ! /(m !(n-m) !)$ combinations of prizes $\mathbf{x}$ that the contestant can face when the next offer is made. Let us denote these combinations by $\mathbf{x}_{1}, \ldots, \mathbf{x}_{\mathbf{C}_{n-m}^{n}}$. Lottery $L(\mathbf{x})$ is then recursively defined by

$$
\begin{aligned}
L(\mathbf{x}) & =\frac{1-\hat{\pi}_{n-m}}{C_{n-m}^{n}} \sum_{i=1}^{C_{n-m}^{n}}\left[L\left(\mathbf{x}_{i}\right) I\left(u\left(L\left(\mathbf{x}_{i}\right), \boldsymbol{\theta}\right) \geq u\left(\hat{O}\left(\mathbf{x}_{i}\right), \boldsymbol{\theta}\right)\right)+\hat{O}\left(\mathbf{x}_{i}\right) I\left(u\left(L\left(\mathbf{x}_{i}\right), \boldsymbol{\theta}\right)<u\left(\hat{O}\left(\mathbf{x}_{i}\right), \boldsymbol{\theta}\right)\right)\right]+ \\
& +\frac{\hat{\pi}_{n-m}}{C_{n-m}^{n}} \sum_{i=1}^{C_{n-m}^{n}} L\left(\mathbf{x}_{i}\right)
\end{aligned}
$$

where $\hat{O}\left(\mathbf{x}_{i}\right)$ is the expectation of a future "bank" offer for $\mathbf{x}_{i}$ prizes left in the unopened boxes and $\hat{\pi}_{n-m}$ is the expected probability that the "bank" offers a swap option instead of a monetary amount at the stage when $n-m$ boxes remain unopened. ${ }^{8}$ Notice that we use a fully rational forward looking algorithm for calculating the reduced form of lottery

\footnotetext{
${ }^{7}$ In the Italian and the British version of Deal or No Deal the "bank" does not make any further monetary offers when a monetary offer for two prizes is rejected. Therefore, in this case a dynamic decision problem coincides with a static decision problem because there are no anticipated "bank" offers in the future.

${ }^{8}$ For any two lotteries $L_{1}\left(y_{1}, p_{1} ; \ldots ; y_{k}, p_{k}\right)$ and $L_{2}\left(z_{1}, q_{1} ; \ldots ; z_{l}, q_{l}\right)$ a compound lottery $\alpha L_{1}+(1-\alpha) L_{2}, \alpha \in[0,1]$, is defined in the usual way-it yields outcome $y_{i}$ with probability $\alpha \cdot p_{i}$, $i \in\{1, \ldots, k\}$, and outcome $z_{j}$ with probability $(1-\alpha) \cdot q_{j}, j \in\{1, \ldots, l\}$.
} 
$L(\mathbf{x})$. An alternative approach is to derive an approximation of lottery $L(\mathbf{x})$ by means of Monte Carlo simulations.

If a decision theory satisfies the independence axiom, e.g. EUT or RN, the utility of lottery $L(\mathbf{x})$ can be conveniently calculated through a Bellman optimality equation

$$
u(L(\mathbf{x}), \boldsymbol{\theta})=\frac{1}{C_{n-m}^{n}} \sum_{i=1}^{C_{n-m}^{n}}\left[\left(1-\hat{\pi}_{n-m}\right) \max \left\{u\left(L\left(\mathbf{x}_{i}\right), \boldsymbol{\theta}\right), u\left(\hat{O}\left(\mathbf{x}_{i}\right), \boldsymbol{\theta}\right)\right\}+\hat{\pi}_{n-m} u\left(L\left(\mathbf{x}_{i}\right), \boldsymbol{\theta}\right)\right] .
$$

However, this equation does not hold for generalized non-expected utility theories.

Since "bank" offers are highly correlated with the expected value of the remaining prizes, the expectation of future "bank" offers $\hat{O}\left(\mathbf{x}_{i}\right)$ is calculated by means of a simple regression $\ln \hat{O}\left(\mathbf{x}_{i}\right)=\hat{\beta}_{0}+\hat{\beta}_{1} \ln E V\left(\mathbf{x}_{i}\right)$, where estimates of coefficients $\hat{\beta}_{0}$ and $\hat{\beta}_{1}$ are taken from Table 1 and Table 2 and $E V\left(\mathbf{x}_{i}\right)$ is the expected value of prizes $\mathbf{x}_{i}$, $i \in\left\{1, \ldots, C_{n-m}^{n}\right\}$. Probability $\hat{\pi}_{n-m}$ is equal to the actual probability with which the "bank" made a swap offer in our recorded sample. In Deal or No Deal UK the "bank" made swap offers instead of a monetary offer only in the first offer in the game. Therefore, probability $\hat{\pi}_{n-m}$ is set equal to zero for the British dataset.

Estimation of a random utility model in a dynamic decision problem deserves special attention. In a random utility model, preferences of a decision maker change each time when a new decision is made. Thus, it is not immediately clear how such individual forms expectations about own future decisions. We assume the simplest possible scenario that contestants expect to keep on maximizing their current preferences (as captured by current parameters of decision theory) while making decisions in the future. 
Table 6 shows maximum likelihood estimates for a dynamic decision problem in Affari Tuoi. In our sample the "bank" made only 2 offers $(0.5 \%)$ higher than the expected value of the remaining prizes. Thus, the estimates for $\mathrm{RN}$ are identical for a static and a dynamic problem, because contestants anticipate that future offers will be less than actuarially fair, and hence they will be always rejected by a risk neutral decision maker.

\begin{tabular}{|c|c|c|c|c|c|}
\hline \multirow{2}{*}{ Decision theory } & \multirow[b]{2}{*}{ Tremble } & \multicolumn{3}{|c|}{ Fechner model of random errors } & \multirow[b]{2}{*}{$\begin{array}{c}\text { Random } \\
\text { utility }\end{array}$} \\
\hline & & $\begin{array}{l}\text { Homo- } \\
\text { scedastic }\end{array}$ & $\begin{array}{l}\text { Hetero- } \\
\text { scedastic }\end{array}$ & $\begin{array}{c}\text { Hetero- } \\
\text { scedastic \& } \\
\text { truncated }\end{array}$ & \\
\hline $\mathbf{R N}$ & $\begin{array}{l}p=0.1603 \\
L L=-179.2\end{array}$ & $\begin{array}{l}\sigma=68685 \\
L L=-225.8\end{array}$ & $\begin{array}{l}\sigma=0.1697 \\
L L=-196.8\end{array}$ & $\begin{array}{l}\sigma=0.3267 \\
L L=-174.2\end{array}$ & $L L=-\infty$ \\
\hline EUT + CRRA & $\begin{array}{l}p=0.1603 \\
r=0 \\
L L=-179.2\end{array}$ & $\begin{array}{l}\sigma=176.74 \\
r=0.4542 \\
L L=-205.5\end{array}$ & $\begin{array}{l}\sigma=0.1413 \\
r=0.1929 \\
L L=-193.1\end{array}$ & $\begin{array}{l}\sigma=1.6139 \\
r=0.2820 \\
L L=-165.8\end{array}$ & $\begin{array}{l}\mu=-0.1201 \\
\sigma=0.8935 \\
L L=-166.04\end{array}$ \\
\hline $\mathbf{E U T}+\mathbf{E P}$ & $\begin{array}{l}p=0.1063 \\
r=-0.3389 \\
\alpha=-0.0013 \\
L L=-168.9\end{array}$ & $\begin{array}{l}\sigma=52612 \\
r=-0.2213 \\
\alpha=2.42 \cdot 10^{-6} \\
L L=-174.7\end{array}$ & $\begin{array}{l}\sigma=0.1487 \\
r=-0.2052 \\
\alpha=2.37 \times 10^{-6} \\
L L=-171.8\end{array}$ & $\begin{array}{l}\sigma=1.7651 \\
r=-0.1564 \\
\alpha=2.2 * 10^{-6} \\
L L=-157.4\end{array}$ & $\begin{array}{l}\mu=-0.7846 \\
\sigma=1.1035 \\
\alpha=1.0^{*} 10^{-6} \\
L L=-153.8\end{array}$ \\
\hline RT (SSB) & $\begin{array}{l}p=0.1603 \\
r=0 \\
\delta=1 \\
L L=-179.2\end{array}$ & $\begin{array}{l}\sigma=24.828 \\
r=-0.0270 \\
\delta=0.4127 \\
L L=-197.7\end{array}$ & $\begin{array}{l}\sigma=0.1401 \\
r=0.2107 \\
\delta=1.0548 \\
L L=-193.1\end{array}$ & $\begin{array}{l}\sigma=4.4475 \\
r=0.0371 \\
\delta=0.6201 \\
L L=-164.2\end{array}$ & $\begin{array}{l}\mu=-0.2926 \\
\sigma=1.0905 \\
\delta=0.7420 \\
L L=-165.94\end{array}$ \\
\hline YDM & $\begin{array}{l}p=0.1603 \\
\gamma=1 \\
L L=-179.2\end{array}$ & $\begin{array}{l}\sigma=38430 \\
\gamma=0.3113 \\
L L=-203.1\end{array}$ & $\begin{array}{l}\sigma=0.1743 \\
\gamma=0.5347 \\
L L=-177.2\end{array}$ & $\begin{array}{l}\sigma=0.3174 \\
\gamma=1.8288 \\
L L=-168.3\end{array}$ & $\begin{array}{l}\mu=1.3618 \\
\sigma=1.0818 \\
L L=-173.4\end{array}$ \\
\hline RDEU & $\begin{array}{l}p=0.1603 \\
r=0 \\
\gamma=1 \\
L L=-179.2\end{array}$ & $\begin{array}{l}\sigma=273.15 \\
r=0.4244 \\
\gamma=0.6192 \\
L L=-194.0\end{array}$ & $\begin{array}{l}\sigma=0.1640 \\
r=0.0204 \\
\gamma=0.5133 \\
L L=-176.9\end{array}$ & $\begin{array}{l}\sigma=1.1057 \\
r=0.2712 \\
\gamma=1.1106 \\
L L=-165.8\end{array}$ & $\begin{array}{l}\mu=-0.1336 \\
\sigma=0.9089 \\
\gamma=1.0201 \\
L L=-166.03\end{array}$ \\
\hline DAT & $\begin{array}{l}p=0.1603 \\
r=0 \\
\beta=0 \\
L L=-179.2\end{array}$ & $\begin{array}{l}\sigma=3.3624 \\
r=0.9619 \\
\beta=-0.9857 \\
L L=-171.9\end{array}$ & $\begin{array}{l}\sigma=0.6134 \\
r=0.6286 \\
\beta=-0.9999 \\
L L=-169.6\end{array}$ & $\begin{array}{l}\sigma=9.6590 \\
r=0.2902 \\
\beta=-0.0213 \\
L L=-165.8\end{array}$ & $\begin{array}{l}\mu=-0.0903 \\
\sigma=0.8754 \\
\beta=-0.0230 \\
L L=-165.99\end{array}$ \\
\hline
\end{tabular}

Table 6 Maximum likelihood estimates of parameters of decision theories embedded in different models of stochastic choice and obtained log-likelihood values (data from Affari Tuoi, dynamic decision problem) 
Table 6 also shows that the estimates of all decision theories embedded in a tremble model are identical for a static and a dynamic decision problem. Moreover, for all theories that have $\mathrm{RN}$ as a special case, the estimates are the same as for $\mathrm{RN}$. This accidental result is driven by a mass point in "bank" offers. In our recorded sample of Affari Tuoi 9 offers (2.2\%) are exactly equal to the expected value of the remaining prizes (4 of these offers were accepted). $\mathrm{RN}$ embedded in a tremble model predicts that the loglikelihood of observing contestants' decisions on these offers is $9 \cdot \log (1 / 2)$. Any other decision theory that does not assume perfect risk neutrality predicts that the loglikelihood of observing contestants' decisions on these offers is $4 \log (p)+5 \log (1-p)$ or $5 \log (p)+4 \log (1-p)$ where $p$ is a probability of a tremble. When $p$ is small, each of these $\log$-likelihood values is significantly lower than $9 \cdot \log (1 / 2)$, which handicaps nonRN theories. For example, Figure 3 in Appendix shows that the log-likelihood functions of EUT and YDM have a sizeable spike corresponding to a special case of RN.

A comparison of Table 3 and Table 6 shows that all decision theories embedded in a random utility model provide a better fit to the data in a dynamic rather than a static decision problem. Theories embedded in a Fechner model also tend to have a better fit in a dynamic decision problem (especially in a Fechner model with heteroscedastic errors). However, this result is never statistically significant and for some decision theories embedded in a Fechner model the fit is actually worse in the dynamic decision problem.

Estimated parameters of decision theories are similar in a dynamic and a static decision problem and Result 1 holds. Interestingly, the standard deviation of stochastic parameters in a random utility model tends to be higher but the variance of random errors in a Fechner model tends to be lower in a dynamic decision problem. Thus, a higher dispersion of preferences but a lower dispersion of random errors is required for explaining individual decision making in a dynamic problem. 
Result 2 holds for all theories except for EUT with EP utility function. However, for any decision theory except for $\mathrm{RN}$ there is no significant difference between its prediction in a Fechner model with heteroscedastic truncated errors and its prediction in a random utility model. This comes as a result of improvement in the prediction of a random utility model in a dynamic problem compared to a static problem (whereas the prediction of a Fechner model did not change significantly).

Table 7 compares the fit of two most successful theories within every model. Result 3 clearly holds in Table 7. The best fit to the data is provided by EUT with EP utility function when it is embedded in either a Fechner model with heteroscedastic truncated errors or a random utility model.

\begin{tabular}{|c|c|c|c|c|c|c|c|c|c|c|c|}
\hline \multirow{2}{*}{$\begin{array}{l}\text { Stochastic } \\
\text { Choice } \\
\text { Model } \\
\quad \downarrow \\
\end{array}$} & \multirow{2}{*}{$\begin{array}{c}\longrightarrow \\
\begin{array}{c}\text { Decision } \\
\text { Theory }\end{array} \\
\end{array}$} & \multicolumn{2}{|c|}{$\begin{array}{c}\text { Tremble } \\
\text { Model }\end{array}$} & \multicolumn{2}{|c|}{$\begin{array}{c}\text { Fechner model, } \\
\text { homoscedastic } \\
\text { errors }\end{array}$} & \multicolumn{2}{|c|}{$\begin{array}{c}\text { Fechner model, } \\
\text { heteroscedastic } \\
\text { errors }\end{array}$} & \multicolumn{2}{|c|}{$\begin{array}{c}\text { Fechner model, } \\
\text { heteroscedastic } \\
\text { truncated errors }\end{array}$} & \multicolumn{2}{|c|}{$\begin{array}{c}\text { Random } \\
\text { Utility Model }\end{array}$} \\
\hline & & $\begin{array}{c}\text { EUT+ } \\
\text { EP } \\
\end{array}$ & $\mathbf{R N}$ & DAT & \begin{tabular}{|c|} 
EUT+ \\
EP
\end{tabular} & DAT & \begin{tabular}{|c|} 
EUT+ \\
EP \\
\end{tabular} & $\begin{array}{c}\text { EUT+ } \\
\text { EP } \\
\end{array}$ & \begin{tabular}{|c|} 
RT \\
(SSB)
\end{tabular} & $\begin{array}{c}\text { EUT+ } \\
\text { EP }\end{array}$ & $\begin{array}{c}\text { RT } \\
\text { (SSB) }\end{array}$ \\
\hline \multirow{2}{*}{ 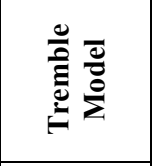 } & $\begin{array}{c}\text { EUT+ } \\
\text { EP }\end{array}$ & - & & $\begin{array}{c}0.3513 \\
(0.3627) \\
\end{array}$ & $\begin{array}{c}6.7160 \\
(0.0000) \\
\end{array}$ & \begin{tabular}{|c|}
0.0869 \\
$(0.4654)$ \\
\end{tabular} & $\begin{array}{c}0.3159 \\
(0.3760) \\
\end{array}$ & & & & \\
\hline & $\mathbf{R N}$ & & - & & & & & & & & \\
\hline \multirow{2}{*}{ 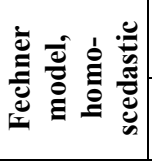 } & DAT & & & & & & & & & & \\
\hline & $\begin{array}{c}\text { EUT+ } \\
\text { EP }\end{array}$ & & & & - & & & & & & \\
\hline \multirow{2}{*}{ 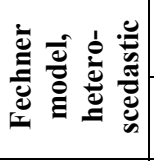 } & DAT & & \begin{tabular}{|c|}
1.9433 \\
$(0.0260)$ \\
\end{tabular} & $\begin{array}{c}0.8866 \\
(0.1877) \\
\end{array}$ & & - & & \begin{tabular}{|l}
-1.8456 \\
$(0.0325)$ \\
\end{tabular} & & & \begin{tabular}{|c|}
-0.7919 \\
$(0.2142)$ \\
\end{tabular} \\
\hline & $\begin{array}{c}\text { EUT+ } \\
\text { EP }\end{array}$ & & $\begin{array}{c}0.5816 \\
(0.2804)\end{array}$ & & $\begin{array}{c}7.9990 \\
(0.0000) \\
\end{array}$ & & - & $\begin{array}{l}-1.9501 \\
(0.0256) \\
\end{array}$ & & & $\begin{array}{c}-0.7006 \\
(0.2418) \\
\end{array}$ \\
\hline \multirow{2}{*}{ 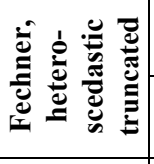 } & $\begin{array}{c}\text { EUT+ } \\
\text { EP }\end{array}$ & \begin{tabular}{|c|}
1.4208 \\
$(0.0777)$ \\
\end{tabular} & \begin{tabular}{|c|}
2.4603 \\
$(0.0069)$ \\
\end{tabular} & $\begin{array}{c}2.6116 \\
(0.0045) \\
\end{array}$ & \begin{tabular}{|c|}
7.1385 \\
$(0.0000)$ \\
\end{tabular} & \begin{tabular}{|c|}
1.8456 \\
$(0.0325)$ \\
\end{tabular} & $\begin{array}{c}1.9501 \\
(0.0256) \\
\end{array}$ & 1 & $\begin{array}{c}1.3797 \\
(0.0838) \\
\end{array}$ & \begin{tabular}{|l|}
-0.5785 \\
$(0.2815)$ \\
\end{tabular} & \begin{tabular}{|c|}
1.0409 \\
$(0.1490)$ \\
\end{tabular} \\
\hline & $\begin{array}{c}\text { RT } \\
\text { (SSB) }\end{array}$ & $\begin{array}{c}0.5242 \\
(0.3001) \\
\end{array}$ & \begin{tabular}{|c|}
2.4175 \\
$(0.0078)$ \\
\end{tabular} & $\begin{array}{c}5.5139 \\
(0.0000) \\
\end{array}$ & \begin{tabular}{|c|}
6.2497 \\
$(0.0000)$ \\
\end{tabular} & $\begin{array}{c}1.6047 \\
(0.0543) \\
\end{array}$ & \begin{tabular}{|c|}
0.9556 \\
$(0.1696)$ \\
\end{tabular} & \begin{tabular}{|c|}
-1.3797 \\
$(0.0838)$ \\
\end{tabular} & & \begin{tabular}{|c|}
-0.1764 \\
$(0.4300)$ \\
\end{tabular} & \begin{tabular}{|c|c|}
0.3388 \\
$(0.3674)$ \\
\end{tabular} \\
\hline \multirow{2}{*}{ 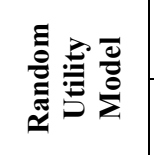 } & $\begin{array}{c}\text { EUT+ } \\
\text { EP }\end{array}$ & $\begin{array}{c}0.6348 \\
(0.2628)\end{array}$ & $\begin{array}{c}1.5190 \\
(0.0644)\end{array}$ & $\begin{array}{c}1.0573 \\
(0.1452) \\
\end{array}$ & $\begin{array}{c}6.0319 \\
(0.0000) \\
\end{array}$ & \begin{tabular}{|c|}
0.7727 \\
$(0.2199)$ \\
\end{tabular} & \begin{tabular}{|c|}
0.8438 \\
$(0.1994)$ \\
\end{tabular} & $\begin{array}{c}0.5785 \\
(0.2815) \\
\end{array}$ & $\begin{array}{c}0.1764 \\
(0.4300)\end{array}$ & - & \begin{tabular}{|c|}
0.3396 \\
$(0.3671)$ \\
\end{tabular} \\
\hline & $\begin{array}{c}\text { RT } \\
\text { (SSB) }\end{array}$ & $\begin{array}{c}0.2862 \\
(0.3874)\end{array}$ & \begin{tabular}{|c|}
2.0415 \\
$(0.0206)$
\end{tabular} & $\begin{array}{c}1.1736 \\
(0.1203)\end{array}$ & $\begin{array}{c}5.9889 \\
(0.0000)\end{array}$ & \begin{tabular}{|c|}
0.7919 \\
$(0.2142)$
\end{tabular} & $\begin{array}{c}0.7006 \\
(0.2418)\end{array}$ & \begin{tabular}{|c|}
-1.0409 \\
$(0.1490)$
\end{tabular} & $\begin{array}{c}-0.3388 \\
(0.3674)\end{array}$ & \begin{tabular}{|c|}
-0.3396 \\
$(0.3671)$
\end{tabular} & - \\
\hline
\end{tabular}

Table 7 Vuong non-nested likelihood ratio test ( $p$-value) of selected pairs of a decision theory and a stochastic choice model (Affari Tuoi, dynamic problem). A significantly positive (negative) value indicates that a row (column) pair is closer to the true data generating process than a column (row) pair. Akaike Information Criterion is used to adjust for a smaller number of parameters in RN. 


\begin{tabular}{|c|c|c|c|c|c|}
\hline \multirow{2}{*}{ Decision theory } & \multirow[b]{2}{*}{ Tremble } & \multicolumn{3}{|c|}{ Fechner model of random errors } & \multirow[b]{2}{*}{$\begin{array}{c}\text { Random } \\
\text { utility }\end{array}$} \\
\hline & & $\begin{array}{l}\text { Homo- } \\
\text { scedastic }\end{array}$ & $\begin{array}{l}\text { Hetero- } \\
\text { scedastic }\end{array}$ & \begin{tabular}{|c|} 
Hetero- \\
scedastic \& \\
truncated
\end{tabular} & \\
\hline $\mathbf{R N}$ & $\begin{array}{l}p=0.1476 \\
L L=-586.8\end{array}$ & $\begin{array}{l}\sigma=17767 \\
L L=-638.5\end{array}$ & $\begin{array}{l}\sigma=0.1144 \\
L L=-610.6\end{array}$ & $\begin{array}{l}\sigma=0.3264 \\
L L=-462.7\end{array}$ & $L L=-\infty$ \\
\hline EUT + CRRA & $\begin{array}{l}p=0.1365 \\
r=0.2530 \\
L L=-557.7\end{array}$ & $\begin{array}{l}\sigma=325.03 \\
r=0.3128 \\
L L=-545.7\end{array}$ & $\begin{array}{l}\sigma=0.0719 \\
r=0.2709 \\
L L=-537.7\end{array}$ & $\begin{array}{l}\sigma=0.5043 \\
r=0.1294 \\
L L=-458.5\end{array}$ & $\begin{array}{l}\mu=0.0945 \\
\sigma=0.6433 \\
L L=-453.1\end{array}$ \\
\hline $\mathbf{E U T}+\mathbf{E P}$ & $\begin{array}{l}p=0.0844 \\
r=-0.3842 \\
\alpha=-0.00157 \\
L L=-510.1\end{array}$ & $\begin{array}{l}\sigma=972091 \\
r=-0.5903 \\
\alpha=1.5^{*} 10^{-7} \\
L L=-483.4\end{array}$ & $\begin{array}{l}\sigma=0.1847 \\
r=-0.7031 \\
\alpha=5.9 * 10^{-8} \\
L L=-490.0\end{array}$ & $\begin{array}{l}\sigma=2.9243 \\
r=-0.1630 \\
\alpha=3.0 * 10^{-6} \\
L L=-441.2\end{array}$ & $\begin{array}{l}\mu=-1.8088 \\
\sigma=2.2528 \\
\alpha=1.2 * 10^{-7} \\
L L=-548.0\end{array}$ \\
\hline RT (SSB) & $\begin{array}{l}p=0.1299 \\
r=0.3955 \\
\delta=1.7181 \\
L L=-544.6\end{array}$ & $\begin{array}{l}\sigma=754.55 \\
r=0.3829 \\
\delta=1.2239 \\
L L=-543.0\end{array}$ & $\begin{array}{l}\sigma=0.0677 \\
r=0.3446 \\
\delta=1.2903 \\
L L=-528.0\end{array}$ & $\begin{array}{l}\sigma=0.2992 \\
r=0.2726 \\
\delta=1.7111 \\
L L=-455.9\end{array}$ & $\begin{array}{l}\mu=0.3075 \\
\sigma=0.3865 \\
\delta=1.8155 \\
L L=-440.8\end{array}$ \\
\hline YDM & $\begin{array}{l}p=0.1422 \\
\gamma=1.3583 \\
L L=-572.2\end{array}$ & $\begin{array}{l}\sigma=13133 \\
\gamma=0.4031 \\
L L=-544.1\end{array}$ & $\begin{array}{l}\sigma=0.0942 \\
\gamma=0.4787 \\
L L=-469.4\end{array}$ & $\begin{array}{l}\sigma=0.2897 \\
\gamma=1.5018 \\
L L=-445.4\end{array}$ & $\begin{array}{l}\mu=0.8003 \\
\sigma=0.4019 \\
L L=-498.3\end{array}$ \\
\hline RDEU & $\begin{array}{l}p=0.1287 \\
r=0.3218 \\
\gamma=0.6758 \\
L L=-537.0\end{array}$ & $\begin{array}{l}\sigma=275.67 \\
r=0.3304 \\
\gamma=0.6076 \\
L L=-488.1\end{array}$ & $\begin{array}{l}\sigma=0.0834 \\
r=0.1842 \\
\gamma=0.5868 \\
L L=-457.1\end{array}$ & $\begin{array}{l}\sigma=0.2097 \\
r=-0.2617 \\
\gamma=2.5316 \\
L L=-439.9\end{array}$ & $\begin{array}{l}\mu=0.1957 \\
\sigma=0.4479 \\
\gamma=0.7747 \\
L L=-444.6\end{array}$ \\
\hline DAT & $\begin{array}{l}p=0.1344 \\
r=0.0012 \\
\beta=0.5214 \\
L L=-552.1\end{array}$ & $\begin{array}{l}\sigma=0.3968 \\
r=1.1045 \\
\beta=-0.9726 \\
L L=-467.9\end{array}$ & $\begin{array}{l}\sigma=0.4470 \\
r=0.7370 \\
\beta=-0.9999 \\
L L=-506.0\end{array}$ & $\begin{array}{l}\sigma=0.1965 \\
r=-0.2442 \\
\beta=1.7651 \\
L L=-442.4\end{array}$ & $\begin{array}{l}\mu=0.0321 \\
\sigma=0.6430 \\
\beta=0.1083 \\
L L=-451.9\end{array}$ \\
\hline
\end{tabular}

Table 8 Maximum likelihood estimates of parameters of decision theories embedded in different models of stochastic choice and obtained log-likelihood values (data from Deal or No Deal UK, dynamic decision problem)

Table 8 shows maximum likelihood estimates for a dynamic decision problem in Deal or No Deal UK. In the British version of the show, only 4 monetary offers $(0.3 \%)$ are more than actuarially fair. Thus, contestants do not expect that the "bank" offers a sure amount higher than the expected value of possible prizes. Hence, risk neutral individuals anticipate that they always reject "bank" offers in the future and the estimates of $\mathrm{RN}$ are identical in static and dynamic decision problems. The estimates of all decision theories embedded in a tremble model and their goodness of fit are nearly identical in 
static and dynamic problems even though there is no mass point in "bank" offers in Deal or No Deal UK (only 4 offers, or $0.3 \%$, are exactly equal to the expected value of possible prizes). Theories embedded in a Fechner model provide either better or the same goodness of fit in a dynamic problem as in a static problem (except for EUT with EP utility function and RDEU in a Fechner model of homoscedastic errors). All theories, except for EUT with EP utility function, embedded in a random utility model provide significantly better fit to the data in a dynamic decision problem.

Result 1 holds in Table 8 (for instance, the estimated coefficients of YDM, RDEU and DAT vary significantly across different models of stochastic choice). Estimated parameters of decision theories and models of stochastic choice are generally similar in dynamic and static decision problems. However, there are few noticeable differences. Maximum likelihood estimate of EUT with EP utility function shows that contestants exhibit increasing absolute risk aversion $(r<0)$ in all models. The standard deviation of a stochastic parameter of all decision theories except for YDM embedded in a random utility model is higher in a dynamic problem.

Result 2 holds for all decision theories except for EUT with CRRA utility function and RT (SSB). Table 9 compares the fit of two most successful theories within every model of stochastic choice. Result 3 continues to hold: EUT with EP utility function is the best descriptive decision theory in a tremble model, DAT - in a Fechner model of homoscedastic errors, RDEU—in the remaining two Fechner models, and RT (SSB) or RDEU—in a random utility model. The best fit to the data across all models of stochastic choice is provided by RDEU or EUT with EP utility function embedded in a Fechner model with heteroscedastic truncated errors or by RT (SSB) embedded in a random utility model. However, Clarke test indicates that the decisions of contestants are most accurately described by RT (SSB) or RDEU embedded in a random utility model. 


\begin{tabular}{|c|c|c|c|c|c|c|c|c|c|c|c|}
\hline \multirow{2}{*}{$\begin{array}{c}\text { Stochastic } \\
\text { Choice } \\
\text { Model } \\
\quad \downarrow\end{array}$} & \multirow{2}{*}{$\begin{array}{l}\longrightarrow \\
\begin{array}{c}\text { Decision } \\
\text { Theory }\end{array} \\
\end{array}$} & \multicolumn{2}{|c|}{$\begin{array}{c}\text { Tremble } \\
\text { Model }\end{array}$} & \multicolumn{2}{|c|}{\begin{tabular}{|c|}
$\begin{array}{c}\text { Fechner model, } \\
\text { homoscedastic } \\
\text { errors }\end{array}$ \\
\end{tabular}} & \multicolumn{2}{|c|}{$\begin{array}{c}\text { Fechner model, } \\
\text { heteroscedastic } \\
\text { errors }\end{array}$} & \multicolumn{2}{|c|}{$\begin{array}{c}\text { Fechner model, } \\
\text { heteroscedastic } \\
\text { truncated errors }\end{array}$} & \multicolumn{2}{|c|}{$\begin{array}{c}\text { Random } \\
\text { Utility Model }\end{array}$} \\
\hline & & $\begin{array}{c}\text { EUT+ } \\
\text { EP }\end{array}$ & RDEU & DAT & \begin{tabular}{|c|} 
EUT+ \\
EP
\end{tabular} & RDEU & YDM & RDEU & \begin{tabular}{|c|} 
EUT+ \\
EP \\
\end{tabular} & $\begin{array}{c}\text { RT } \\
\text { (SSB) }\end{array}$ & RDEU \\
\hline \multirow{2}{*}{ 总 } & $\begin{array}{c}\text { EUT+ } \\
\text { EP }\end{array}$ & - & $\begin{array}{c}1.1753 \\
(0.1199) \\
\end{array}$ & \begin{tabular}{|c|}
-2.9218 \\
$(0.0017)$ \\
\end{tabular} & $\begin{array}{c}-1.5451 \\
(0.0612) \\
\end{array}$ & \begin{tabular}{|c|}
-2.5116 \\
$(0.0060)$ \\
\end{tabular} & \begin{tabular}{|c|}
-1.9985 \\
$(0.0228)$ \\
\end{tabular} & \begin{tabular}{|c|}
-3.9906 \\
$(0.0000)$ \\
\end{tabular} & \begin{tabular}{|l|}
-5.8016 \\
$(0.0000)$ \\
\end{tabular} & \begin{tabular}{|c|}
-3.3941 \\
$(0.0003)$ \\
\end{tabular} & \begin{tabular}{|c|}
-3.2344 \\
$(0.0006)$ \\
\end{tabular} \\
\hline & RDEU & $\begin{array}{r}-1.1753 \\
(0.1199) \\
\end{array}$ & & $\begin{array}{c}-4.1799 \\
(0.0000) \\
\end{array}$ & & $\begin{array}{c}-6.5246 \\
(0.0000) \\
\end{array}$ & \begin{tabular}{|l|}
-5.3821 \\
$(0.0000)$ \\
\end{tabular} & \begin{tabular}{|l|}
-7.2772 \\
$(0.0000)$ \\
\end{tabular} & & & \\
\hline \multirow{2}{*}{ 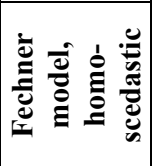 } & DAT & $\begin{array}{c}2.9218 \\
(0.0017)\end{array}$ & $\begin{array}{c}4.1799 \\
(0.0000)\end{array}$ & - & \begin{tabular}{|c|}
0.8918 \\
$(0.1862)$ \\
\end{tabular} & $\begin{array}{c}-0.8464 \\
(0.1987) \\
\end{array}$ & $\begin{array}{c}0.0439 \\
(0.4825) \\
\end{array}$ & $\begin{array}{c}-2.6414 \\
(0.0041) \\
\end{array}$ & & $\begin{array}{l}-2.1207 \\
(0.0170) \\
\end{array}$ & \\
\hline & RDEU & $\begin{array}{c}1.5451 \\
(0.0612)\end{array}$ & \begin{tabular}{|c|}
2.6762 \\
$(0.0037)$
\end{tabular} & $\begin{array}{c}-0.8918 \\
(0.1862)\end{array}$ & - & & \begin{tabular}{|c|}
-0.8174 \\
$(0.2069)$
\end{tabular} & \begin{tabular}{|c|}
-2.7552 \\
$(0.0029)$ \\
\end{tabular} & & \begin{tabular}{|c|}
-2.4208 \\
$(0.0077)$
\end{tabular} & \\
\hline \multirow{2}{*}{ 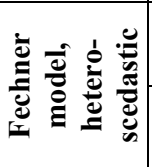 } & RDEU & $\begin{array}{c}2.5116 \\
(0.0060)\end{array}$ & $\begin{array}{c}6.5246 \\
(0.0000)\end{array}$ & $\begin{array}{c}0.8464 \\
(0.1987)\end{array}$ & $\begin{array}{c}1.4919 \\
(0.0679)\end{array}$ & - & \begin{tabular}{|c|}
2.1691 \\
$(0.0150)$
\end{tabular} & \begin{tabular}{|l|}
-1.6544 \\
$(0.0490)$ \\
\end{tabular} & \begin{tabular}{|l|}
-1.1500 \\
$(0.1251)$
\end{tabular} & & \begin{tabular}{|c|}
-1.0952 \\
$(0.1367)$ \\
\end{tabular} \\
\hline & YDM & $\begin{array}{c}1.9985 \\
(0.0228)\end{array}$ & \begin{tabular}{|c|}
5.3821 \\
$(0.0000)$
\end{tabular} & $\begin{array}{c}-0.0439 \\
(0.4825)\end{array}$ & $\begin{array}{c}0.8174 \\
(0.2069)\end{array}$ & \begin{tabular}{|c|}
-2.1691 \\
$(0.0150)$
\end{tabular} & - & \begin{tabular}{|l|}
-3.2280 \\
$(0.0006)$ \\
\end{tabular} & \begin{tabular}{|l|}
-2.1156 \\
$(0.0172)$
\end{tabular} & \begin{tabular}{|c|}
-2.3019 \\
$(0.0107)$
\end{tabular} & \begin{tabular}{|c|}
-1.9562 \\
$(0.0252)$ \\
\end{tabular} \\
\hline \multirow{2}{*}{ 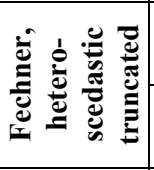 } & RDEU & $\begin{array}{c}3.9906 \\
(0.0000) \\
\end{array}$ & $\begin{array}{c}7.2772 \\
(0.0000)\end{array}$ & $\begin{array}{c}2.6414 \\
(0.0041) \\
\end{array}$ & $\begin{array}{c}2.7552 \\
(0.0029)\end{array}$ & $\begin{array}{c}1.6544 \\
(0.0490) \\
\end{array}$ & $\begin{array}{c}3.2280 \\
(0.0006) \\
\end{array}$ & - & \begin{tabular}{|c|}
0.1559 \\
$(0.4380)$ \\
\end{tabular} & $\begin{array}{c}0.0673 \\
(0.4732) \\
\end{array}$ & $\begin{array}{c}0.3570 \\
(0.3605) \\
\end{array}$ \\
\hline & $\begin{array}{c}\text { EUT+ } \\
\text { EP }\end{array}$ & $\begin{array}{c}5.8016 \\
(0.0000) \\
\end{array}$ & $\begin{array}{c}5.8346 \\
(0.0000) \\
\end{array}$ & $\begin{array}{c}3.1809 \\
(0.0007) \\
\end{array}$ & $\begin{array}{c}2.8918 \\
(0.0019) \\
\end{array}$ & $\begin{array}{c}1.1500 \\
(0.1251) \\
\end{array}$ & $\begin{array}{c}2.1156 \\
(0.0172) \\
\end{array}$ & \begin{tabular}{|c|}
-0.1559 \\
$(0.4380)$
\end{tabular} & - & \begin{tabular}{|c|}
-0.0286 \\
$(0.4886)$
\end{tabular} & \begin{tabular}{|c|}
0.2345 \\
$(0.4073)$ \\
\end{tabular} \\
\hline \multirow{2}{*}{ 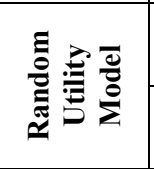 } & $\begin{array}{c}\text { RT } \\
\text { (SSB) }\end{array}$ & $\begin{array}{c}3.3941 \\
(0.0003)\end{array}$ & $\begin{array}{c}5.7865 \\
(0.0000)\end{array}$ & $\begin{array}{c}2.1207 \\
(0.0170)\end{array}$ & $\begin{array}{c}2.4208 \\
(0.0077)\end{array}$ & $\begin{array}{c}1.4886 \\
(0.0683)\end{array}$ & \begin{tabular}{|c|}
2.3019 \\
$(0.0107)$
\end{tabular} & \begin{tabular}{|c|}
-0.0673 \\
$(0.4732)$
\end{tabular} & $\begin{array}{c}0.0286 \\
(0.4886)\end{array}$ & - & \begin{tabular}{|c|}
1.1766 \\
$(0.1197)$
\end{tabular} \\
\hline & RDEU & $\begin{array}{c}3.2344 \\
(0.0006)\end{array}$ & $\begin{array}{c}5.4530 \\
(0.0000)\end{array}$ & $\begin{array}{c}1.8113 \\
(0.0351)\end{array}$ & \begin{tabular}{|c|}
2.2243 \\
$(0.0131)$
\end{tabular} & $\begin{array}{c}1.0952 \\
(0.1367)\end{array}$ & \begin{tabular}{|c|}
1.9562 \\
$(0.0252)$
\end{tabular} & \begin{tabular}{|c|}
-0.3570 \\
$(0.3605)$
\end{tabular} & \begin{tabular}{|l|}
-0.2345 \\
$(0.4073)$
\end{tabular} & \begin{tabular}{|c|}
-1.1766 \\
$(0.1197)$
\end{tabular} & - \\
\hline
\end{tabular}

Table 9 Vuong non-nested likelihood ratio test ( $p$-value) of selected pairs of a decision theory and a stochastic choice model (Deal or No Deal UK, dynamic problem). A significantly positive (negative) value indicates that a row (column) pair is closer to the true data generating process than a column (row) pair. Akaike Information Criterion is used to adjust for a smaller number of parameters in YDM.

Both in static and dynamic decision problems, EUT with CRRA utility function always yields significantly worse fit to the data than EUT with EP utility function, except when EUT is embedded in a random utility model in Deal or No Deal UK dataset. Thus, constant relative risk aversion is ill-suited for decision problems that involve both small and large monetary outcomes. Constant absolute risk aversion generally cannot be rejected in a static decision problem (especially when EUT is embedded in a Fechner model). However, in a dynamic problem the estimated coefficient $r$ of EUT with EP utility function is always significantly different from zero. Thus, constant absolute risk aversion appears to be inappropriate functional form for dynamic decision problems. 
Notice that when decision theories are embedded in a Fechner model of homoscedastic errors, the best fit to the data is provided by DAT. This confirms the finding of Camerer and Ho (1994) who reexamine the data from 11 laboratory studies and conclude that DAT provides "surprisingly good fit" when decision theories are estimated in a strong utility model, which is equivalent to our Fechner model of homoscedastic random errors.

EUT with CRRA utility function embedded in a Fechner model of heteroscedastic truncated errors fits the data significantly better than RDEU embedded in a Fechner model of homoscedastic errors. This confirms the finding of Blavatskyy (2007) who reexamines the data from 10 laboratory studies and concludes that EUT embedded in a Fechner model with heteroscedastic truncated errors generally fit the data at least as good as rank-dependent theories embedded in a Fechner model with homoscedastic errors.

\section{Conclusion}

Decisions of heterogeneous individuals aggregated through the representative agent approach or repeated decisions of the same individual are often internally inconsistent and cannot be described by a deterministic decision theory on its own. Thus, such decisions are usually described by a deterministic theory embedded in a model of stochastic choice. Comparisons between different theories all embedded in the same model of stochastic choice are popular in an empirical research (e.g. Hey and Orme, 1994). A less common approach is to compare the goodness of fit of different models all combined with the same decision theory. This paper embarks on an enterprise of organizing a round-robin tournament between different decision theories embedded in different models of stochastic choice. The results of this tournament are quite striking. 
The estimated parameters of the same decision theory vary significantly when the theory is embedded into different models of stochastic choice. Thus, estimates of decision theories should be regarded as conditional on the selected model of stochastic choice. Moreover, various assumptions on individual risk attitudes (e.g. regret or disappointment aversion) may be satisfied in one model of stochastic choice and rejected in another. Therefore, when a researcher exogenously picks a model of stochastic choice, this has a profound effect on the estimated parameters of decision theories, which ultimately affects the drawn conclusions about their descriptive validity.

If a model of stochastic choice is selected endogenously, decision theories generally provide the best description of observed decisions when embedded in a Fechner model with heteroscedastic errors drawn from a truncated distribution (e.g. Blavatskyy, 2007). In this model, the variance of errors is higher for lotteries with a wider range of possible prizes. Distribution of errors is truncated so that an individual always rejects sure amounts below the lowest possible prize in a risky lottery and always accepts amounts above the highest possible prize. This stochastic choice model is so superior to other models that the worst performing decision theory (risk neutrality) incorporated into this model fits the data significantly better or at least as good as any decision theory embedded in any other model (except for RDEU embedded into a Fechner model with heteroscedastic errors).

Which decision theory provides the best description of the data generally depends on the selected model of stochastic choice. For example, researchers who use a tremble model (e.g. Harless and Camerer, 1994) would conclude that EUT with expo-power utility function yields the best goodness of fit. Researchers, who use a Fechner model of 
homoscedastic errors (e.g. Hey and Orme, 1994; Camerer and Ho, 1994) would claim that the most accurate description of the data is given by DAT. Last but not least, researchers who use a Fechner model of heteroscedastic truncated errors would conclude that the best decision theory is either EUT with expo-power utility function or RDEU. The last result confirm the finding of Buschena and Zilberman (2000) and Blavatskyy (2007) that EUT performs equally well as RDEU when both are incorporated in a Fechner model with heteroscedastic (truncated) errors.

To draw a bottom line, an accurate description of decisions under risk relies on two equally important components - a model of stochastic choice and a decision theory. These two components are mutually dependent and generally neither can be fixed in an exogenous manner. However, for simple binary choices between a risky lottery and a sure amount, that are analyzed in this paper, the appropriate model of stochastic choice appears to be a Fechner model with heteroscedastic truncated errors (or a random utility model in a dynamic decision problem).

\section{References}

Ballinger, T. Parker and Nathaniel T. Wilcox. (1997). "Decisions, error and heterogeneity" Economic Journal 107, 1090-05

Blavatskyy, Pavlo (2007) "Stochastic expected utility theory" Journal of Risk and Uncertainty forthcoming

Blavatskyy, Pavlo and Ganna Pogrebna (2006) "Loss Aversion? Not with Half-a-Million on the Table!" IEW WP 274 available at www.iew.unizh.ch/wp/iewwp274.pdf

Blavatskyy, Pavlo and Ganna Pogrebna (2007) "Risk Aversion When Gains Are Likely and Unlikely: Evidence from a Natural Experiment with Large Stakes” Theory and Decision, forthcoming 
Buschena, David and David Zilberman. (2000). "Generalized Expected Utility, Heteroscedastic Error, and Path Dependence in Risky Choice" Journal of Risk and Uncertainty 20, 67-88

Camerer, F. Colin (1989) "An experimental test of several generalized utility theories." Journal of Risk and Uncertainty 2, 61-104

Camerer, F. Colin and Teck-Hua Ho. (1994). "Violations of the Betweenness Axiom and Nonlinearity in Probability" Journal of Risk and Uncertainty 8, 167-196

Carbone, Enrica (1997) "Investigation of stochastic preference theory using experimental data” Economics Letters 57, 305-311

Chew, Soo-Hong (1983) "A generalization of the quazilinear mean with applications to the measurement of income inequality and decision theory resolving the Allais paradox" Econometrica 51, 1065-1092

Chew, Soo-Hong and McCrimmon, Kenneth (1979) "Alpha-nu choice theory: an axiomatization of expected utility" University of British Columbia working paper \#669

Clarke, A. Kevin (2003) "Nonparametric Model Discrimination in International Relations" Journal of Conflict Resolution 47(1), 72-93

Fishburn, C. Peter (1983) "Transitive measurable utility" Journal of Economic Theory 31, 293-317

Gul, Faruk (1991) “A Theory of Disappointment Aversion” Econometrica 59, 667-686

Harless, David and Colin F. Camerer. (1994). The predictive utility of generalized expected utility theories, Econometrica 62, 1251-1289

Hey, D. John (1995) "Experimental investigations of errors in decision making under risk" European Economic Review 39, 633-640

Hey, D. John (2005) "Why we should not be silent about noise" Experimental Economics $8325-345$

Hey, D. John and Chris Orme (1994) Investigating generalisations of expected utility theory using experimental data, Econometrica 62, 1291-1326

Holt, Charles and Susan Laury (2002) "Risk Aversion and Incentive Effects" American Economic Review 92, 1644-1655 
Loomes, Graham, Peter Moffatt and Robert Sugden (2002) "A microeconomic test of alternative stochastic theories of risky choice" Journal of Risk and Uncertainty 24, $103-130$

Loomes, Graham, Chris Starmer, and Robert Sugden (1992) "Are preferences monotonic? Testing some predictions of regret theory" Economica 59, 17-33

Loomes, Graham and Robert Sugden (1995) "Incorporating a stochastic element into decision theories" European Economic Review 39, 641-648

Luce, R. Duncan (1959) Individual choice behaviour New York, John Wiley and Sons

Luce, R. Duncon and Patrick Suppes (1965) "Preference, utility, and subjective probability" in R. D. Luce, R. R. Bush \& E. Galanter (eds.), Handbook of mathematical psychology, Vol. III, 249-410, Wiley, New York NY

Pogrebna, Ganna (2007) "Naive Advice When Half-a-Million is at Stake" Economics Letters forthcoming

Post, Thierry, Martijn Van den Assem, Guido Baltussen and Richard Thaler, (2006) "Deal or No Deal? Decision Making Under Risk in a Large-Payoff Game Show" available at SSRN: $\underline{\text { http://ssrn.com/abstract }=636508}$

Quiggin, John. (1981). "Risk perception and risk aversion among Australian farmers" Australian Journal of Agricultural Recourse Economics 25, 160-169

Starmer, Chris (2000) "Developments in non-expected utility theory: the hunt for a descriptive theory of choice under risk" Journal of Economic Literature 38, 332-382

Starmer, Chris and Robert Sugden (1989) "Probability and juxtaposition effects: An experimental investigation of the common ratio effect." Journal of Risk and Uncertainty 2, 159-178

Tversky, Amos and Daniel Kahneman (1992) “Advances in Prospect Theory: Cumulative Representation of Uncertainty" Journal of Risk and Uncertainty 5, 297-323

Vuong, H. Quang (1989) "Likelihood ratio tests for model selection and non-nested hypotheses" Econometrica 57, 307-333

Yaari, E. Menahem (1987) "The Dual Theory of Choice under Risk" Econometrica 55, 95-115 


\section{Appendix}

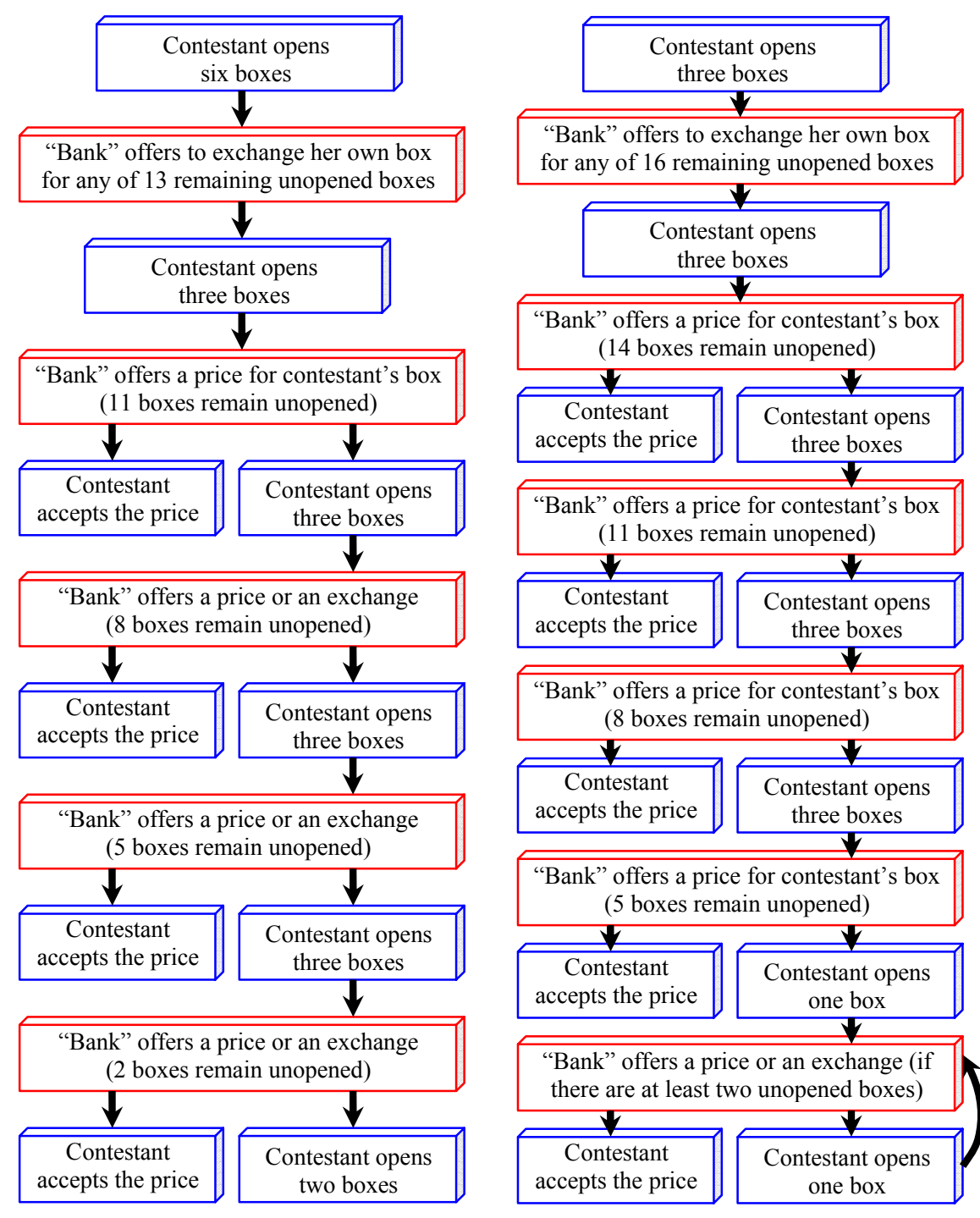

Figure 1 Timing of "bank" offers in Affari Tuoi television episodes before February 9, 2006 (left chart) and starting from February 9, 2006 (right chart)

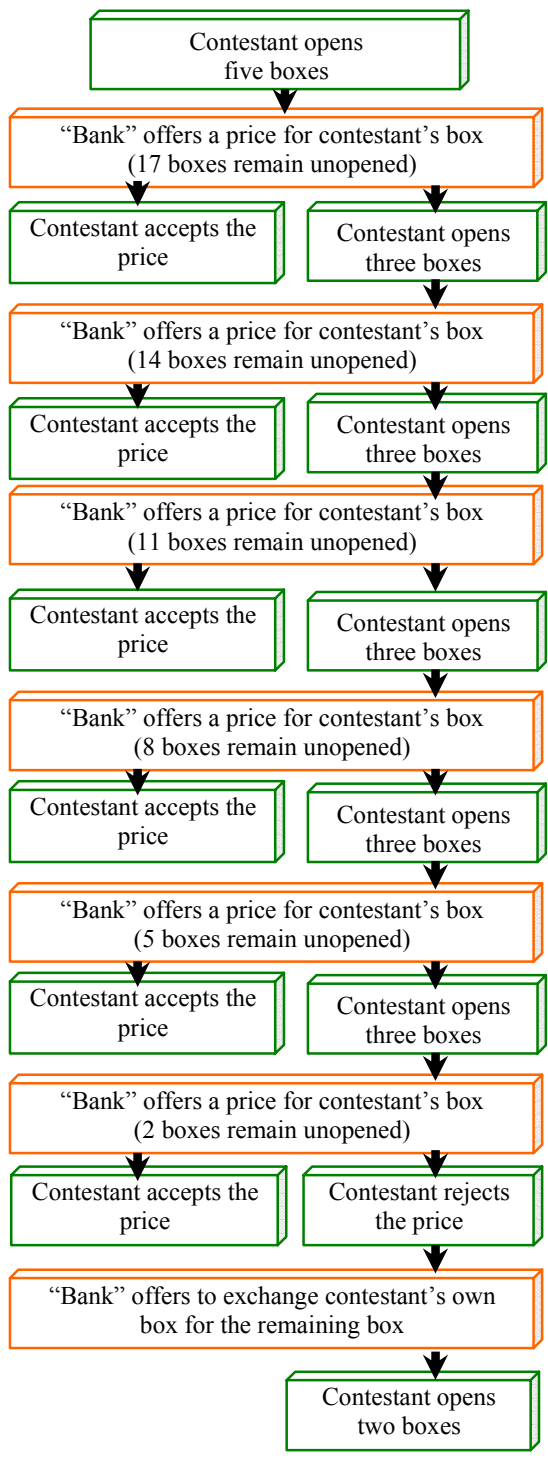

Figure 2 Timing of "bank" offers in Deal or No Deal UK television episodes 
Log-likelihood Function of EUT with CRRA Utility Function Embedded into a Tremble Model

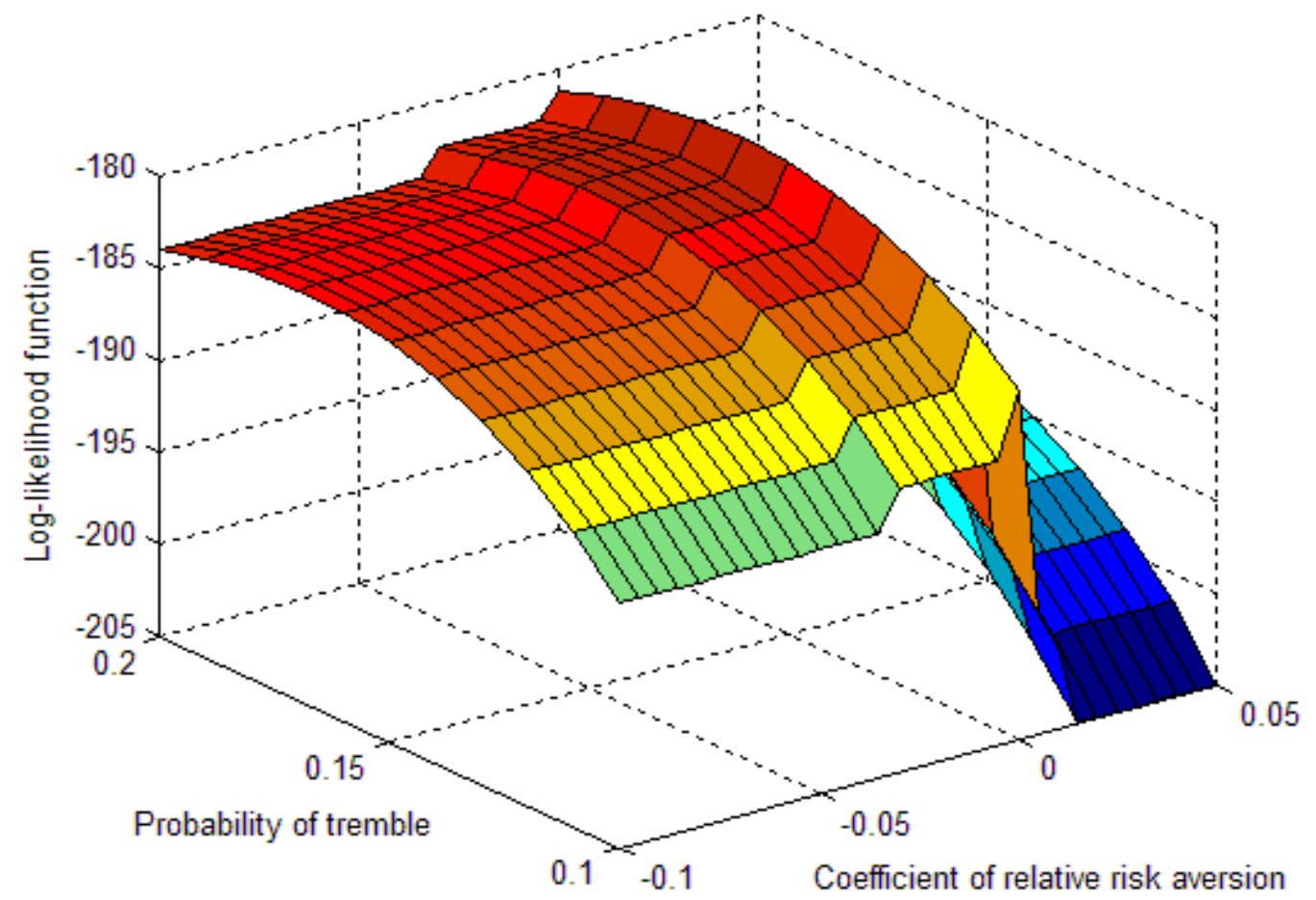

Log-likelihood Function of Yaari's Dual Model Embedded into a Tremble Model

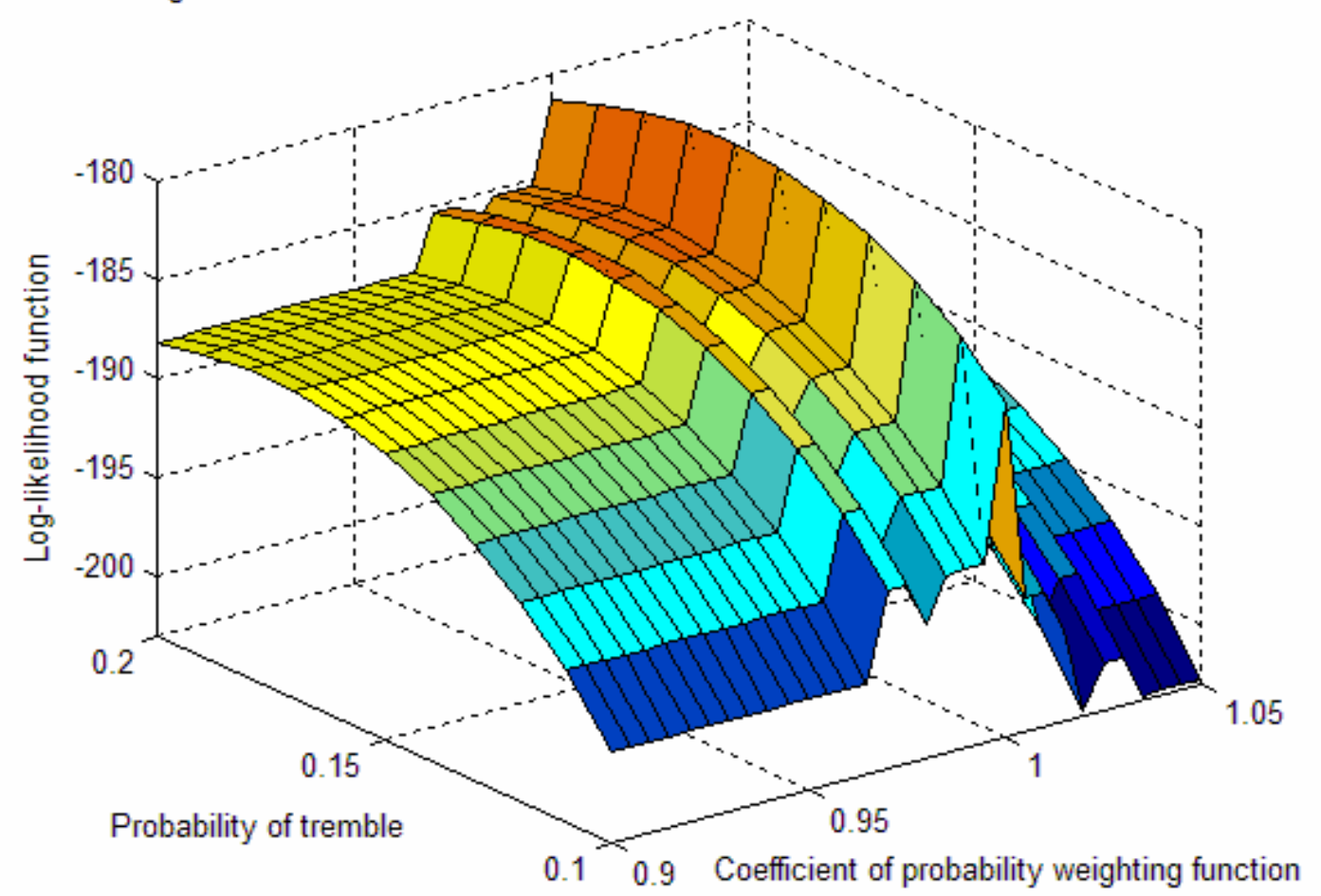

Figure 3 Log-likelihood functions of EUT and YDM embedded into a tremble model 